NBER WORKING PAPER SERIES

Labor Mobility and Wages

Jacob Mincer

Boyan Jovanovic

Working Paper No. $\underline{357}$

NATIONAL BUREAU OF ECONOMIC RESEARCH

1050 Massachusetts Avenue

Cambridge MA 02138

June 1979 
Labor Mobility and Wages

SUMMARY

In this essay we explore the implications of human capital and search behavior for both the interpersonal and life-cycle structure of inter-firm labor mobility. The economic hypothesis which motivates the analysis is that individual differences in firm-specific complementarities and related skill acquisitions produce differences in mobility behavior and in the relation between job tenure, wages and mobility. Both "job duration dependence" and heterogeneity bias" are implied by this theory. Exploration of longitudinal data sets (NLS and MID) which contain mobility, job and wage histories of men in the 1966-76 decade yield the following findings, among others:

1. The initially steep and later decelerating declines of labor mobility with working age are in large part due to the similar but more steeply declining relation between mobility and length of job tenure.

2. Given tenure levels, the probability of moving is predicted positively by the frequency of prior moves and negatively by education. The inclusion of prior moves in the regression reduces the estimated tenure slope because it helps to remove the "heterogeneity bias" in that slope.

3. The popular "mover-stayer model" is rejected by the existence of tenure effects on mobility.

4. Differences in mobility during the first decade of working life do not predict long-run differences in earnings. However, persistent movers at later stages of working life have lower wage levels and flatter life-cycle wage growth.

5. The analysis calls for a reformulation of earnings (wage) functions. Inclusion of tenure terms in the function permits separate estimates of returns to general and specific human capital after correction for heterogeneity bias. A rough estimate is that 50 percent of life-time wage growth is due to general (transferable) experience and 25 percent each to firm-specific experience and inter-firm mobility.

Jacob Mincer

Boyan Jovanovic

809 I.A.B.

Columbia University

New York, N.Y. 10027

(212) $280-3676$ 
1. Introduction: Renewed Interest in Labor Mobility

Labor mobility is one of the central toplcs of labor economics and a long-standing subject of empirical research. Earlier studies reflected primarily a concern with the allocative efficiency of the labor market. They analyzed attitudes, job-change decisions and the direction of observed labor mobility in attempts to ascertain whether information, motivation and behavior of workers were consistent with the postulates of economis theory.

In a comprehensive survey of this literature (Parnes, 1970) the author concluded that the evidence on the operation of market forces was mixed, both among different studies and even within them. Although research in the 1960's was more sophisticated and utilized larger data sets than prior work it did not provide any change in perspective.

Reviewing the more recent literature Parsons (1976) finds promise in the emergence of human capital and of search theories as tools for the analysis of labor mobility, labor turnover, and unemployment. However, applied work in search theory has, thus far, only partially touched on problems of labor mobility and of unemployment: Its emphasis has been largely on conditions terminating job search, rather than on circumstances which generate it.

The reformulation of labor mobility as a human capital investment decision has been fruitfully applied to migration (Sjastaad, 1962, and other work reviewed by Greenwood, 1976). The connection between investments specific to the firm. (and to larger units) and the incidence of

* Part $I$ is an exposition and empirical analysis whch ranges over somewhat wider subject matter than Part II which focuses on the stochastic structure of mobility processes. We are grateful to the National Science Foundation and the Sloan Foundation for support of this work

The research reported here is part of the NBER's program in Labor Economics. Any opinions expressed are those of the authors and not those of the National Bureau of Economic Research. 
industrial and occupational labor turnover has been elucidated in studies of Becker (1962), Oi (1961), and Parsons (1972).

The novel approaches suggested by human capital and by search theories are producing a renewed interest in the formerly stagnant field of labor mobility. A further source of interest has come from stochastic models of labor mobility. These made their initial appearance as the "mover-stayer" model two decades ago (Blumen, Kagan, McCarthy, 1955) and have recently reappeared in more sophisticated form. ${ }^{1}$

The purpose of this essay ${ }^{2}$ is to explore the implications of human capital and search behavior for both the interpersonal and life cycle structure of inter-firm labor mobility. The apparent ambiguity in the relation between labor mobility and wages which characterizes much of the literature surveyed by parnes is implicit and reconcilable in human capital analysis: As a response to perceived gains in wages mobility promotes individual wage growth, but to the extent that on-the-job investments contain elements of specificity, mobility is a deterrent to wage growth. The study of differences in mobility behavior requires information over time: of special importance, in our approach, is information on time spent in the firm (tenure) and on the life-cycle changes in job attachments. The availability of longitudinal microdata lespecially NLS and MID panels) enables us to study these phenomena.

The economic hypothesis which motivates the analysis is that individual differences in firm-specific human capital behavior lead, via wage effects, to heterogeneity in mobility behavior, and to "tenure effects" on attachment to the firm. Implications for life-cycle mobility are then derived in the absence or presence of "aging" (changes in mobility with age, at given tenure levels). Both "tenure dependence" and "hetero- 
geneity bias" are implied by the theory. We explore data sets which contain mobility histories to ascertain the existence of these phenomena and to correct for the predictable biases. Next we investigate corresponding features of the wage structure. Labor mobility and tenure effects are introduced and tested in a reformulated earnings function in which specific and general human capital accumulation can be distinguished. Part II presents a rigorous formulation of the structure of mobility viewed as a stochastic process.

2. Tenure, Working Age, and Mobility: Some Definitions and Facts We define labor mobility as change of employer, whether or not unemployment intervenes. We exclude exits from and entries into the labor force. This exclusion is a minor one for the male labor force which we study. ${ }^{3}$ Consequently, job separation is synonymous with job change in our data. Except for one illustration of observed differences (in Table 2), we do not distinguish here between separations initiated by (or reported as) quit or layoff. Geographic, industrial, and occupational mobility are components of job mobility which are included in our concept but not singled out for separate treatment. 4

Two probabilistic relations, or time-profiles, are basic in our discussion and measurement of labor mobility. (1) The "tenure turnover profile" $S(T)$ is the relation between the probability of separating from $a$ job in period $t$ and the time spent in that job prior to $t$ (current tenure $T$ ). In the language of renewal theory, $S(T)$ is the "hazard function". At the individual level this is a profile of "propensities to move" conditional on tenure. Such a profile is not observable. In large homogeneous groups, that is consisting of individuals with the 
same propensities $S(T)$, we can observe estimates of the probabilities in each period in the form of relative frequencies or separation rates conditional on tenure. (2) The relation between an individual's propensity to move and working age, regardless of his current terure, is his "experience turnover profile" $S(X)$. Again this is observable as a relation between experience and separation rates.

The most firmly established fact about labor mobility of all kinds is that it declines with age. It declines much more sharply with length of tenure. The declines in both $S(X)$ and $S(T)$ are strongest initially and decelerate subsequently. Several tenure and age profiles of separation rates are shown in Tables $1-3$.

Table 1 shows the decline with age in the proportion of job changers (number of job changers divided by number employed) in 1961. The decline is similar when measured in terms of number of job changes rather than job changers, since a similar fraction (35-40 percent) of job movers in each age group changed jobs more than once during the year. 5

Table 2 shows cross-classifications of separations, quits and layoffs by experience and tenure in the period 1971-73 in the two NLS samples of men (young men, ages 19-29 and older men ages 50-64 in 1971). The tenure profiles within working age (experience) classes are steeply declining and decelerating (convex). Mobility does not decline with age at given tenure levels within each of the cohort age ranges. The decline between the young and old cohort is pronounced but it shows mainly in quits.

The separation equations in Table 3 summarize the conclusion that within the two age panels declines of mobility with age (experience), shown by $S(X)$ in Tables 1 and 2 , are due to the effect of tenure which is 
TABLE 1

Job Changers as Percent of Employed Men, U.S., 1961

\begin{tabular}{llllllll}
\hline & \multicolumn{8}{c}{ Age } \\
\cline { 2 - 7 } & $18-19$ & $20-24$ & $25-34$ & $35-44$ & $45-54$ & $55-64$ \\
\hline & & & & & & \\
\hline
\end{tabular}

Source: BIS, Spectal Labor Force Report No. 35. 


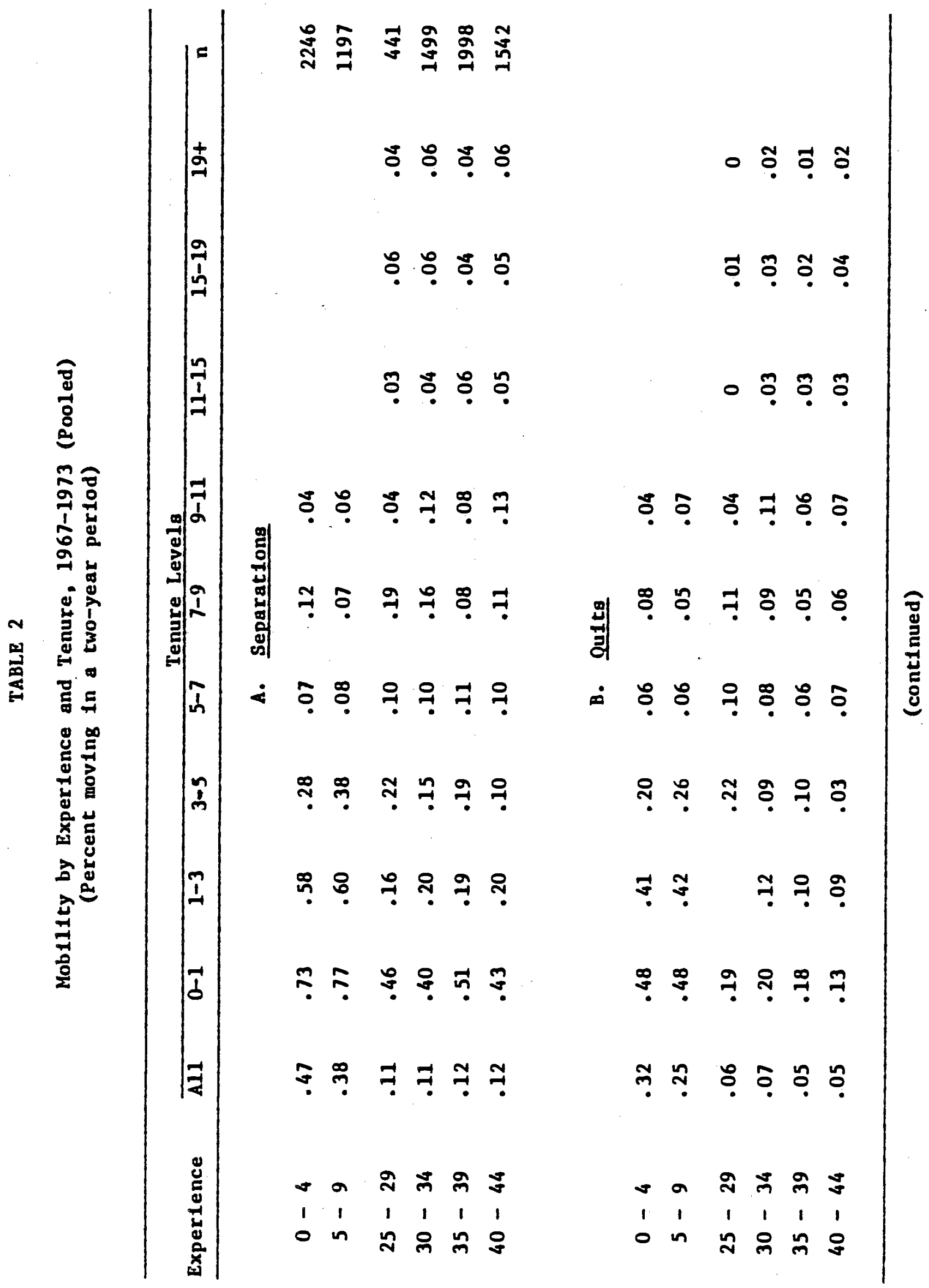




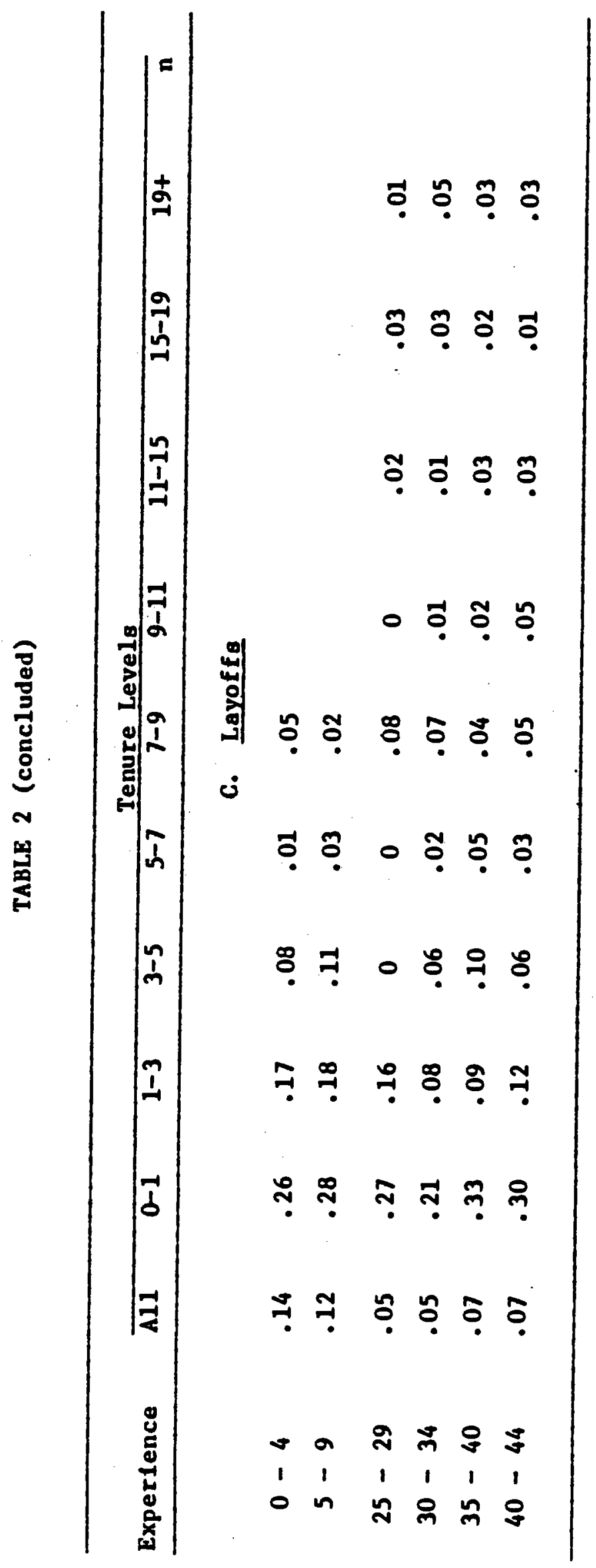


TABLE 3

Separation Equations

Poung Men, Pooled

$$
\begin{aligned}
& S(X)=.486-\underset{(5.2)}{.034 x}+\underset{(3.6)}{.002 x^{2}} \quad R^{2}=.02 \\
& S(X, T)=.692+\underset{(1.0)}{.006 X}-\underset{(0)}{.0000 X^{2}}-\underset{(19.7)}{.172 T}+\underset{(16.3)}{.009 T^{2}} \quad R^{2}=.29
\end{aligned}
$$

\section{Older Men, Pooled}

$$
\begin{aligned}
& S(X)=.015+\underset{(.4)}{.0028 X}-\underset{(.5)}{.000 X^{2}} \quad R^{2}=.003 \\
& S(X, T)=.208+.0035 X-.0000 X^{2}-.024 T+.0005 T^{2} \quad R^{2}=.10 \\
& (.3) \cdot(.2) \quad(6.4) \quad(4.1)
\end{aligned}
$$

Source: NLS Samples of Young and Mature Men. 
revealed in the regression $S(X, T)$ : For young men, experience effects (coefficients of $\mathrm{x}, \mathrm{x}^{2}$ ) vanish when tenure $\left(T, T^{2}\right.$ ) is included. No experience effects are observed for older men with or without the tenure variables. 6 However, estimates of $S(X)$ and $S(X, T)$ in Michigan Income Dynamics data which cover the complete age spectrum (Table 5, Panel C, lines 1 and 2 ) show that net aging effects remain even after the inclusion of tenure, although they are reduced in size and significance. In all data sets the explanatory power resides mainly in the tenure variables; mobility is convex both in tenure and in experience; and the tenure profile is much steeper than the experience profile.

\section{Wage and Mobility Structures: Some Theory}

We now turn to broad theoretical considerations with which we may analyze the facts of labor mobility. Some aspects of skill acquired in a particular firm are not transferable to other firms. The acquisition of such "specific" components of human capital by workers and the consequent wage pattern suffice to produce the tenure effects in the attachment to the firm which we observed in Tables 2 and 3 . At the same time individual differences in amounts of specific capital investment imply a heterogeneity in mobility, or in attachment to the firm (length of tenure) as well as in the strength of tenure effects that is in slopes of the tenure-separation probability relation. The effects of acquiring job specific capital on mobility may be described as follows: Successful job matches eventually result in wage levels $w$ which exceed expected alternative wages $W_{g}$. The higher the wage $W$ the less incentive to quit, given the usual fluctuations in demand. Separations are high during the initial "probation" period and 
drop to low levels. It is reasonable to assume that a successful match is only a starting point for a continuing employment relation which often involves investments of workers and firms in worker skills, and these are partially nontransferable. ${ }^{7}$ Employer investments involve hiring, screening, and training costs which are recouped by wage policy $\mathrm{w}_{\mathrm{g}}<\mathrm{w}$ $<$ VMP, where VMP is the worker's value of marginal product in the firm, so that both quits and layoffs are deterred.

Define $\mathrm{w}=\mathrm{w}_{\mathrm{g}}+\mathrm{w}_{\mathrm{s}}$, where $\mathrm{w}_{\mathrm{g}}$ is the worker return on his general (transferable) human capital and $\mathrm{w}_{\mathbf{S}}$ is the difference between the (higher) wage received in the firm and the opportunity wage elsewhere $\left(w_{g}\right)$. Similarly, $w_{e}$ is the employer's return on the costs of investing in workers, the difference between the worker's productivity (VMP) and the wage paid to him (W). Workers are deterred from quitting and employers from dismissing workers, because of these returns. Total separations are affected by $\Delta=\left(\right.$ VMP $\left.-w_{g}\right)=w_{s}+w_{e}$ that is by both components of returns to specific capital. In this paper we do not focus on the distinction between quit and layoff and do not consider the question whether employers and workers engage in joint or in separate optimizing behavior. ${ }^{8}$ Plausibly, $w_{s}$ and $w_{e}$ are expected to be positively related: a good match and opportunity for joint investments are recognized by both employee and employer.

The distribution of returns to specific capital $(\Delta)$ creates individual (and group) differences in tenure-turnover profiles. Tenure profiles are horizontal only when $\Delta=0$, in which case tenure has no effect on mobility or on wages. With $\Delta>0$, tenure profiles of specific capital does not emerge instantaneously as the worker joins the firm. It is accumulated over time, given a successful match, and the returns grow over time. Both the rate of growth of these returns and their ultimate level affect mobility: 
the "tenure effect" is steeper the bigger both. The convexity of the tenure-mobility profiles, and concavity of the tenure-wage profiles are due to the eventual completion of specific capital accumulation in the firm. 9

Thus the economics of specific human capital formation predicts the coexistence of heterogeneity and of "tenure dependence" in mobility. The two aspects of behavior are related and are not to be viewed as mutually exclusive hypotheses: Persons who favor large volumes of specific capital investment exhibit relatively little mobility ${ }^{10}$ (except $f \propto x$ an initial period of repeated search and occasional later moves) and strong tenure effects. Low levels of specific investment behavior, whether intentional or due to inefficiency in job matching, imply high (persistent) mobility levels independent of tenure (zero or small tenure effects). If rates of decline of experience profiles of mobility reflect primarily the slopes of tenure profiles, as appears to be the case, the flat and high profiles of "movers" and the downward sloping profiles of "stayers" imply a progressive divergence over the life-cycle in observed mobility behavior of a heterogeneous population.

The growing divergence of mobility rates over the working age parallels the repeatedly observed divergence of individual life-cycle wage profiles. ${ }^{11}$ The human capital model can interpret both as lifetime outcomes of unchanging individual differences in abilities and opportunities. This view cautions against literal impressions that older cohorts are more heterogeneous than younger ones, or against the notion that the experience of longer tenure creates a "reinforcement effect" that is a desire to invest in specific capital. This is not to say, however, that such views are not 
valid. Habit formation and unexpected contingencies do modify lifetime histories, but they need not be invoked in an initial analysis.

The major implication of specific capital heterogeneity for the structure of mobility is the existence of differential tenure effects. Levels of $S(T)$ are higher and slopes flatter for individuals and groups who acquire little specificity in their human capital, while steeper slopes and eventually lower levels characterize tenure functions of large specific capital investors. Empirical observations should reveal downward slopes in tenure-turnover profiles exaggerated by "heterogeneity bias", as well as "true" negative slopes after correction for bias. A related set of predictions applies to the wage structure: A major one is the existence of tenure effects on wages which are additional to the effects of general human capital accumulation. This suggests a reformulation of the earnings function to include a tenure term. The experience and tenure coefficients should provide a decomposition of worker returns to general (transferable) and specific (nontransferable) human capital. As in the case of mobility it is also necessary to attempt correction for potential upward biases in tenure effects which are posed by the existence of heterogeneity.

Other implications of the theory relate to age (experience) changes in mobility and wages $S(X)$ and $W(X)$. An interesting conclusion is that mobility declines and wages grow, with age even if there are no "aging" effects, that is even if mobility depended only on levels of tenure and not directly on age (given tenure). Similarly, wages would grow (on average) over the life-cycle even if no general (experience) capital were accumulated. Also $W(X)$ would be concave if $W(T)$ is concave, and $S(X)$ is convex because $S(T)$ is. Indeed, without specific capital 
phenomena the convex shape of the age patterns of mobility $S(X)$ would be difficult to understand.

\section{Tenure Effects on Mobility in Homogeneous and in Heterogeneous Groups}

A simple heuristic model makes the notions intuitively clear: $:^{12}$ The propensity to move at the individual level, or the separation rate in a homogeneous group is a function:

$$
s=f(T, X)
$$

where $s$ is the probability of separation in period $t, T$ is length of current employment in the firm up to time $t$, and $x$ is total work experience (working age). The slope of the age (experience) profile is:

$$
\frac{d s}{d x}=\frac{\partial s}{\partial T} \cdot \frac{d T}{d x}+\frac{\partial s}{\partial x}
$$

Here $\frac{\partial s}{\partial T}$ is the slope of the tenure profile, $\frac{d T}{d x}$ is the growth of tenure with working age, and $\frac{\partial s}{\partial x}$ is the true age effect, if any. Note that $0<\frac{d T}{d x}<1$. Tenure would grow by the same amount of time as age only in the case of perfect immobility: It increases initially with age since it is necessarily short at early stages of experience. At later stages $\frac{d T}{d x}$ approaches zero as $T$ approaches the fixed value $\left(\frac{1}{s}-1\right)$ in the case of no-tenure dependence, that is when $\frac{\partial s}{\partial T}=0$. In the case of job specificity or tenure dependence, i.e., when $\frac{\partial s}{\partial T}<0, \frac{d T}{d x}$ remains positive at later ages as well. ${ }^{13}$ A regression of $T$ on $X$, not shown here, reveals a positive slope and slight concavity.

Decomposition (2) yields the following conclusions about the observed decline of mobility with age: 
1. Even if there were no "age effects" $\left(\frac{\partial s}{\partial x}=0\right)$, mobility would decline with age, because of job specificities, that is because mobility declines with tenure $\frac{\partial s}{\partial T}<0$. No decline would be observed if mobility were independent of tenure. 14

2. Again abstracting from age effects, since $\frac{d T}{d x}<1$, the slope of the experience profile is less than that of the tenure profile.

3. Convexity in the tenure profile would be reinforced or simply reflected in the age profile if $\frac{d T}{d x}$ decreases over time, or is constant. Moreover, this could happen even if there is an age effect and even if the latter were concave.

4. Decline of mobility with age is faster the stronger the decline of mobility with tenure, apart from the pure age effect.

Up to this point the analysis applies to a homogeneous group, defined by the identical $S(X, T)$ function for each of its members. Components of life-cycle mobility can be observed directly in such groups by estimation of equation (1). Generally, it is not possible to define homogeneous groups empirically, so that estimation of (1) cannot be carried out directly. If in fact individual propensities to move are not reduced by tenure yet they differ among workers, the observed group tenure profile $S(T)$ will have a downward slope and is likely to be convex as well. In this case persons with high propensities to move separate at early levels of tenure while those with low propensities stay on a long time. The decline in the tenure profile consequently reflects the degree of heterogeneity when measured by the variance in propensities to move, while convexity would reflect a decline in that variance, as only stayers remain in the long tenure classes. 15 
Let us now define a heterogeneous population in consonance with specific capital heterogeneity as a collection of homogeneous subgroups among which mobility rates differ at given levels of tenure, while tenure curves $S(T)$ decline in some or most of the subgroups. By the preceding argument, any degree of heterogeneity will lend a downward bias (steeper than average slope) to the observed group tenure curve. We should note that heterogeneity biases can exist without any true tenure effects, for reasons not involving specificity. But, if the tenure effect $\left(\frac{\partial s}{\partial T}\right) i$ is zero in each subgroup $i$, the observed population experience profile $S(X)$ will be horizontal, since its slope is an average of slopes in the subgroups. Conversely, if $\left(\frac{\partial s}{\partial T}\right) i<0$ in each or some subgroups the observed experience profile must slope down. Thus, in the absence of age effects, the age profile of mobility $S(X)$ provides a clear test of the presence or absence of tenure effects in the group, regardless of its degree of heterogeneity.

As an example, the popular "mover-stayer" 16 model which assumes heterogeneity and neglects tenure effects must be rejected by the decline in the age-mobility profile, insofar as the latter is not exclusively due to pure age effects $\left(\frac{\partial s}{\partial x}<0\right.$ in (1)).

Although the decline in life-cycle mobility reflects the existence and strength of tenure effects, it yields no information on the extent of heterogeneity in the population. Assessment of heterogeneity is important, however, both in its own right, as well as a basis for recognition and correction of bias in the estimated tenure effects. 


\section{Empirical Mobility Functions}

An open-ended empirical procedure for estimating tenure effects in the presence of heterogeneity is to enter a number of variables which are likely to capture heterogeneous behavior in a regression of tenure on mobility. The tenure slope estimate in the multiple regression is reduced compared to its value when it is the only right-hand variable. The reduction measures the extent of heterogeneity bias due to these variables. This procedure was applied to the NLS data and the results are shown in Table 4, including the list of heterogeneity factors. The reduction in slope was about 20-30 percent for the young men, and larger (relative to the flatter slope) for the older men.

The heterogeneity factors in the regressions were, aside from experience which was also included: education, health, hours of work, family status variables, industry, and union membership. In terms of contribution to $\mathrm{R}^{2}$ the last two factors were the most pronounced. This procedure is clearly incomplete for our purposes here, although of interest in the substantive studies of particular factors.

A scheme that is more general, in the sense that it does not require an enumeration of heterogeneity factors derives from the definition: At a given level of tenure members of a homogeneous group have equal probabilities of moving during the next period regardless of their past mobility, while in a heterogeneous group probabilities differ even at fixed current tenure. Since frequency of past mobility is an indicator of personal probability ("propensity to move") in the heterogeneous case, its (partial) correlation with mobility in the next period, given tenure, reveals the existence and estimates the degree of heterogeneity. And to 


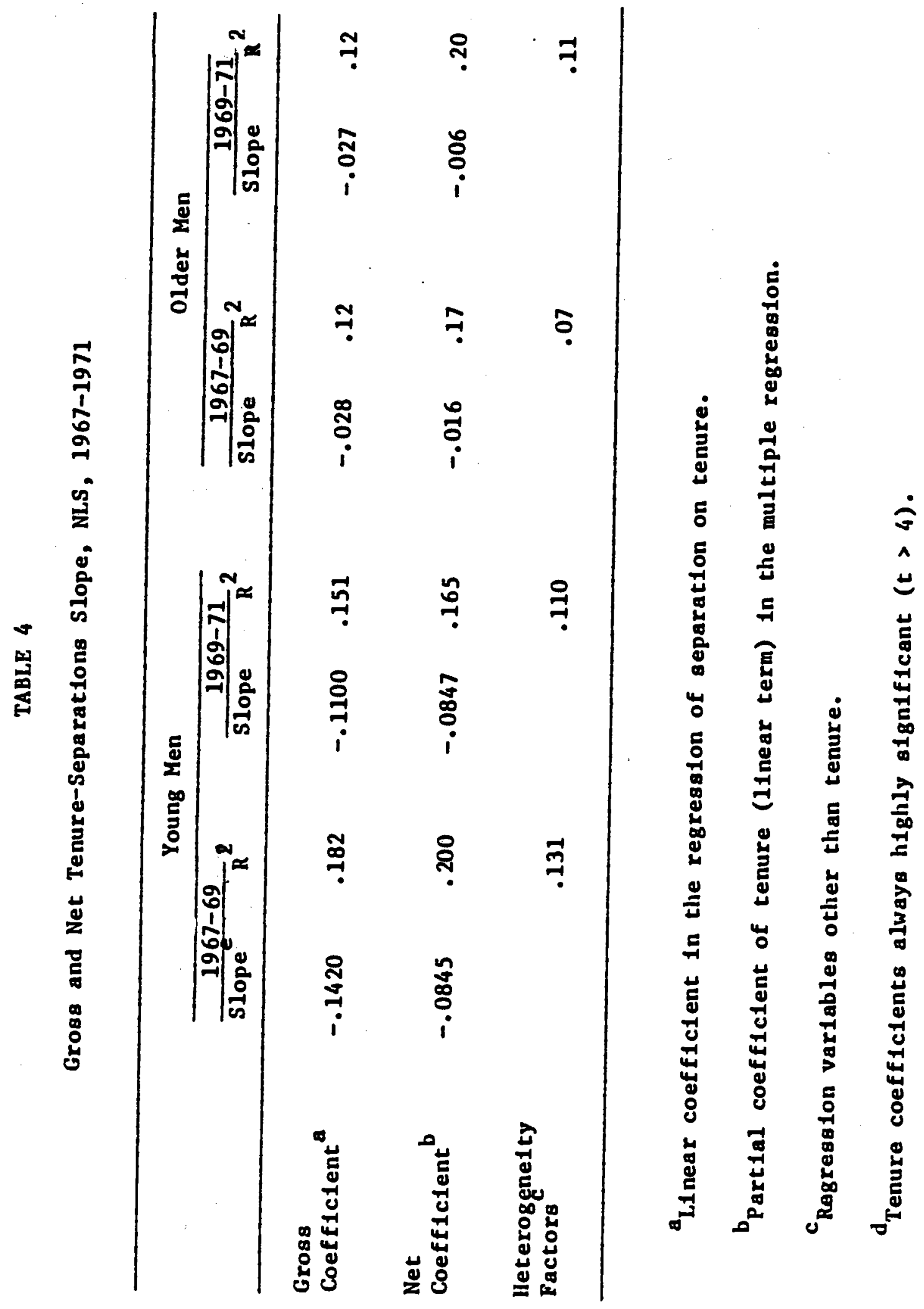


the extent that the prior mobility variable captures and therefore standardizes for differential mobility levels its inclusion corrects the bias in the estimated tenure slope.

Information on prior mobility was available in the NLS data for young men as the number of interfirm moves (NM) between 1966 and 1971 . For the older men in NLS such information was not available, but we constructed a variable (PM) on the number of (survey to survey) periods between 1965 and 1973 during which at least one move took place. ${ }^{17}$

Table 5 presents, in successive steps, regressions for young men (Panel A) in which separations (job changes) in the period 1971-73 are predicted by: years of work experience $\left(X, x^{2}\right)$ up to 1971 , tenure (T, $\left.T^{2}\right)$ in 1971, and mobility prior to the current job (NM). The prior mobility variable was also interacted with experience (XNM). The same regressions (except that PM replaces NM) predict job change rates of NLS older men in 1973-75 (Panel B), and of all MID men in 1975-76 (Panel C).

Briefly, the findings are: Inclusion of tenure (line 2) shows it to be the variable which is responsible for the gross age decline in separations among young NLS men (line 1, Panel A). Looking at lines 1 and 2 of panel B, we find that the older NLS men show neither gross nor net age (experience) effects. While net age effects are absent within the limited age ranges in the NLS data (young $\leq 29$, old $\geq 50$ ) they are reduced (going from line 1 to 2 in panel C) but remain significant in the MID regressions which cover the whole age spectrum. The absence of gross age effects (Iine 1, panel B) in the older cohort reflects very small tenure effects (slopes) at this stage. This is consistent with a strong convexity of tenure (and age) profiles over the long run. The comparable tenure slopes are much steeper for the young because they are dominated in regressions by early tenure levels. 
$\underline{\text { Regression Variables in Tables } 5 \text { and } 6}$

$x$ - years of work experience

$T$ - years of tenure on the current job

Ed - years of schooling

NM - number of interfirm moves in the period 1966-1971 of young men in NLS. Adjusted to length of period if experience started after 1966.

PM - number of 2-year periods between 1965 and 1973 during which a job change occurred among older men in NLS.

SM - number of annual periods between 1968 and 1975 during which a job change occurred among men in MID. Adjusted if work experience started after 1968.

w - logarithm of hourly wage; $\bar{w}$ - mean of $w$

$\bar{s}$ - mean rate of job change (over 2 years in NLS, annual in MID)

n - sample size

$R^{2}$ - adjusted coefficient of determination

t-statistics in parentheses 


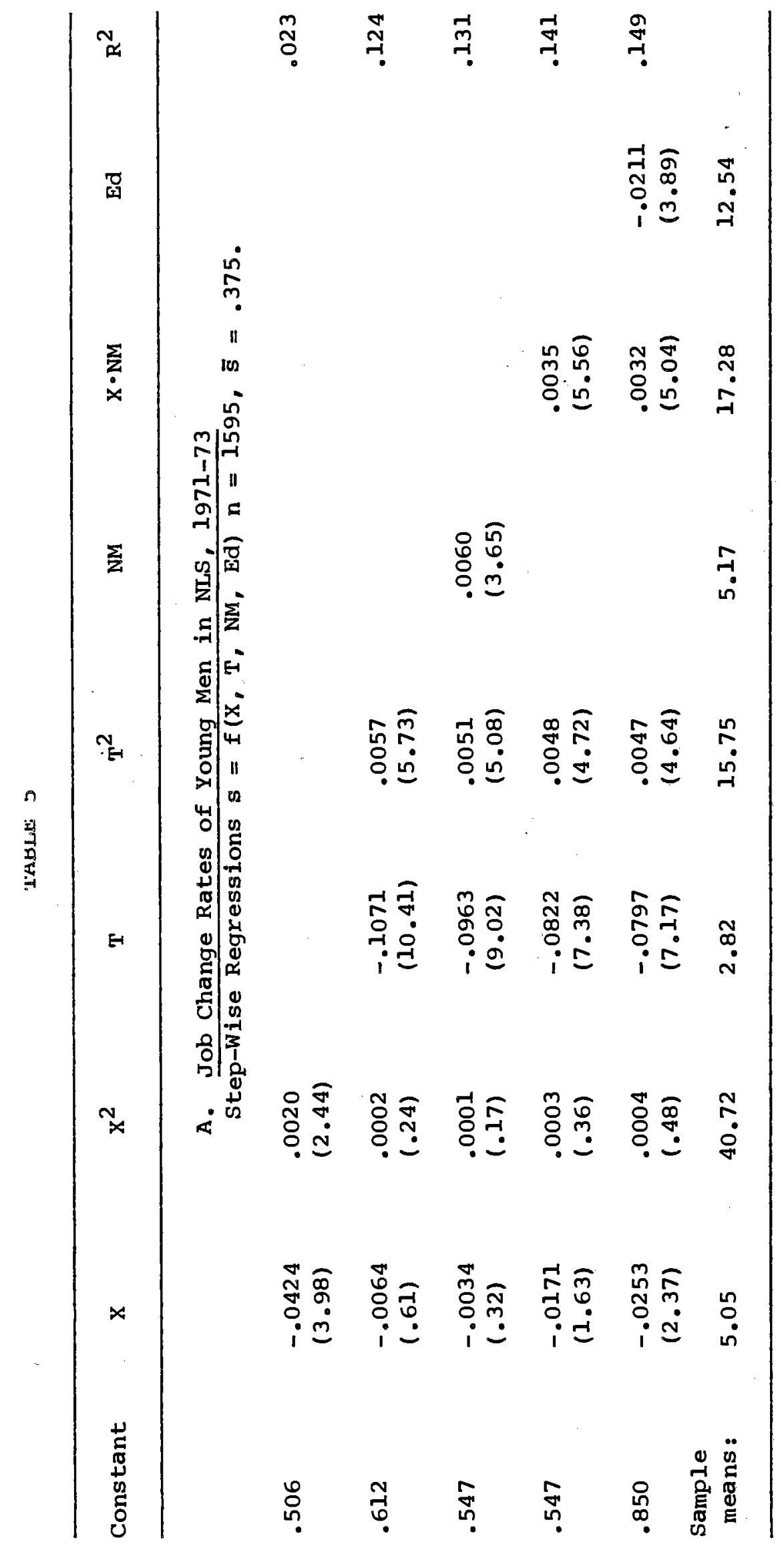




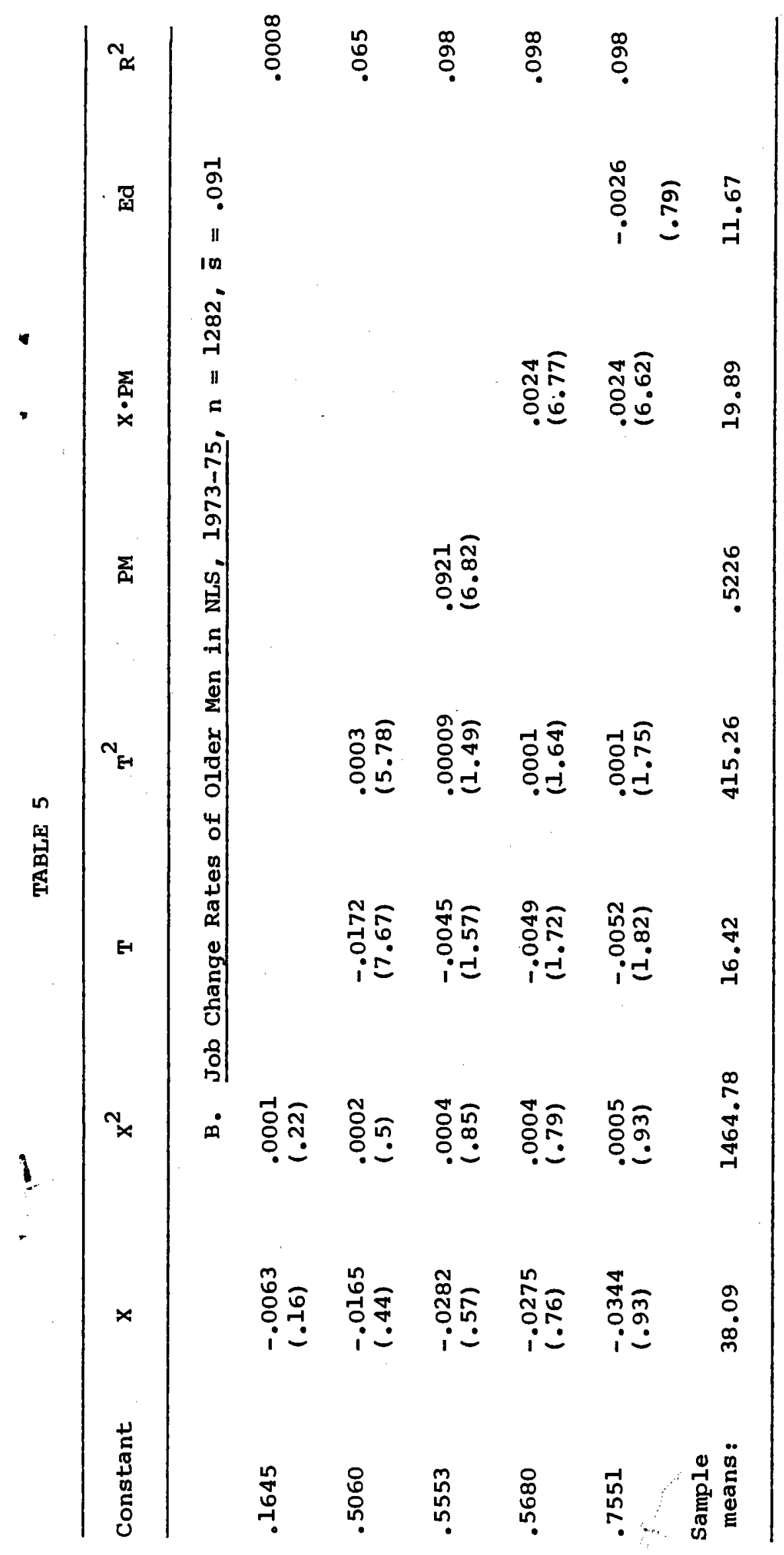




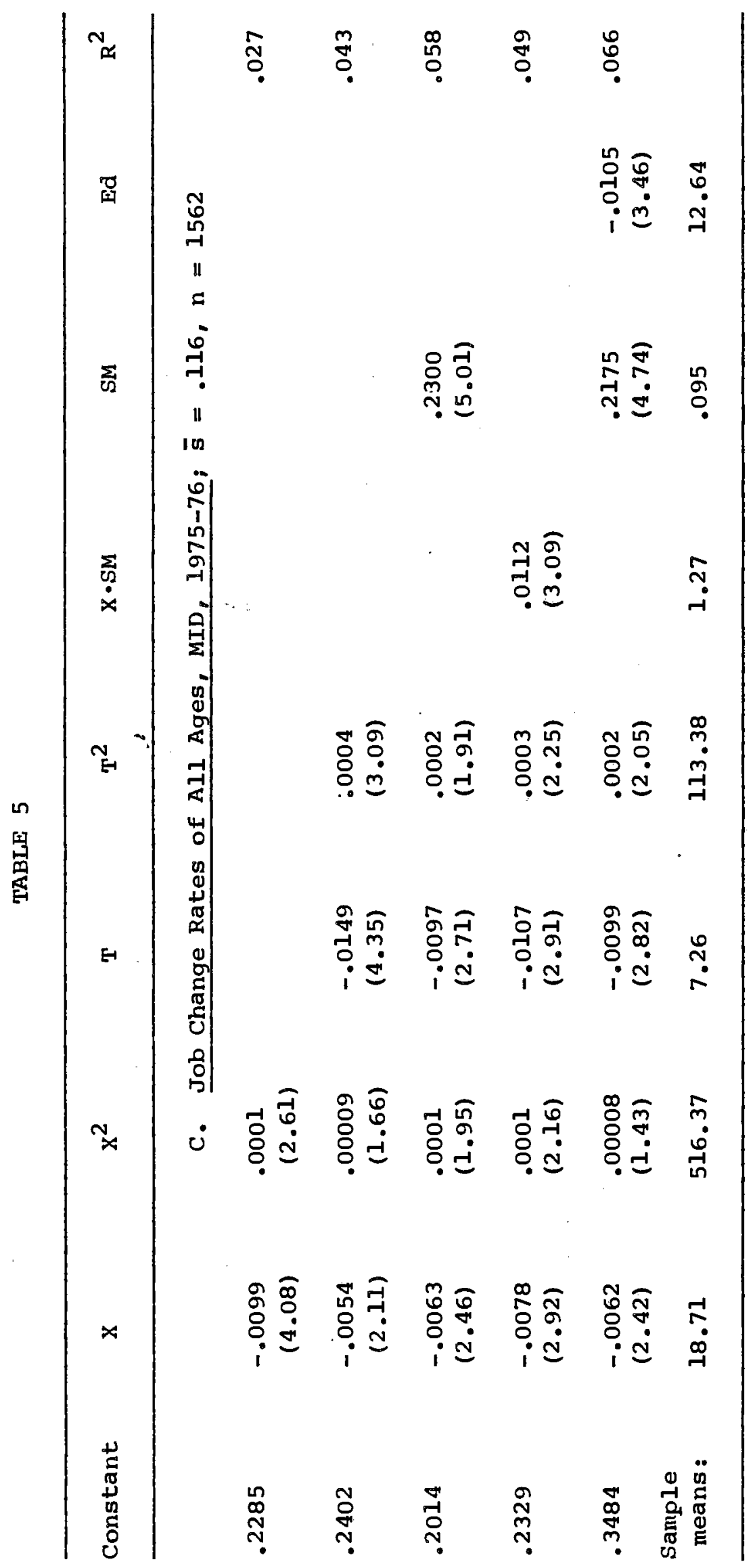


Indeed, in a subsample of older men whose tenure does not exceed 8 years (not shown here), the tenure slopes are quite as steep as those of young men. Thus, the differences between the young and the old need not be interpreted as a change in the mobility structure.

The inclusion of prior mobility variables shows the existence of heterogeneity in mobility behavior: The variable is a strong predictor of mobility in the next period given experience and temure at the beginning of the period. Persons who moved more frequently prior to the current job are more likely to leave the job earlier than others. Prior mobility appears to be a stronger predictor at older than at younger ages. This can be seen in the effect on $\mathrm{R}^{2}$ (i.e. in the partial correlation), and in the regression slope. When converted into an elasticity it is several times larger in the older group. Evidently, repeated mobility at an advanced age represents persistent mobility suggesting little stake in job tenure or lack of opportunity, while repeated mobility at young ages does not have the same connotation. We tried to test the proposition that prior mobility at older ages is a better index of heterogeneity within each of the panels: The experienceprior mobility interaction variable, shown in line 4 of each panel, was positive and significant. Incidentally, the existence of this interaction implies that age (experience) profiles of mobility are not only higher but also flatter for movers (PM large) than for stayers (PM small), as we theorized in section 3 (p.11).

The introduction of the prior mobility variable was designed to separate "movers" from "stayers". If effective, such "standardization" should reduce the tenure slope in the regression. Tenure slopes are 
indeed reduced in all three data panels in lines 3 and below. The reduction is small among the young and large among the old, as would be expected since PM is a stronger indicator of persistent mobility at older ages. The average reduction in the linear tenure term at midexperience levels (MID) is about one-third. That is, heterogeneity biases the steepness of tenure-turnover profile upward by about 50 percent, on average. As predicted, inclusion of prior mobility which is an attempt to. standardize for heterogeneity, reduces the tenure slope by about a third (in the linear term) among the young and by close to twothirds among the old. Incidentally, the education variable shown in the last rows of Table 5 appears to predict some reductions in mobility at given levels of initial mobility, but has no additional predictive power among the old.

\section{Net Age Effects in Mobility}

Although they do not appear in the NLS regression of Table 5, age effects (coefficients of experience $\frac{\partial s}{\partial x}$ ) on mobility are present in the MID regressions in panel $C$ and were seen in the decline of mobility rates at fixed levels of tenure when the older cohort was compared to the younger (Table 2). The economics of this downward shift in tenure curves may be found in the more traditional aspects of labor mobility: Job change is a response to higher wage levels beckoning elsewhere as well as a search for specific investment opportunities.

For a given wage gain, the supply response would diminish with working age (at given levels of tenure) since the payoff period declines. Such effects, however, would not become pronounced until late in the working life, especially in view of positive and not negligible discounting. 
Emphasis on finite life (working age) cannot produce a convex experienceturnover profile, nor can it rationalize the fact that the observed net age declines $\left(\frac{\partial s}{\partial x}\right)$ occur relatively early in the working life. However, the gain from mobility may decline over the life cycle not because of the declining payoff period but because of rising costs: Costs of geographic mobility are sizable and rise with family size and the presence of school-age children.

Age effects are, indeed, more important in migration than in local job mobility. The decline in migration with age $s(x)$ is steeper than the decline in local job mobility: One-third of young compared to less than 10 percent of older job changers migrate. But the greater costs in migration include also costs due to locational specificities which exist in addition to job specificity, so stronger "pure aging" is not the only reason for a sharper age decline in migration than in local job mobility: Tenure effects which reflect both job and location specificities are indeed, sharper for migrants.

Another set of age factors, unrelated to location, may operate in the early years of work experience: The range of quality of jobs and of the job match cannot be ascertained by mere search, and some knowledge must be acquired by actual experimentation. Also, job training and opportunities for investment in general human capital may present themselves sequentially in different firms. Beyond the first decade of working life, we may expect that human capital investors who eventually find a reasonably compatible work place develop a strong attachment to the job.

\section{Tenure and Mobility Effects in the Wage Function}

Specific capital investments imply tenure effects on wages which cause the tenure effects in mobility. Wage heterogeneity due to differ- 
ential specificities similarly produce some of the heterogeneity in mobility. Consequently, we should observe tenure effects in addition to general work experience effects in wage functions. Moreover, these effects may be exaggerated in empirical estimates in view of interpersonal diversity in specific investment behavior.

Information on job mobility can and should be built into the standard earnings function. The inclusion of the tenure variable should capture returns to specific (non-transferable) capital accumulation permitting the experience term to measure returns to general (transferable) capital accumulation. Information on prior mobility should also be useful in correcting for heterogeneity bias. The explanatory power of the enriched wage function ought to be enhanced.

The coefficients of experience $(X)$ in the standard wage function, which includes orly education in addition to the experience terms, reflect a gross effect $\frac{d w}{d x}$ which is a mixture of returns to general and specific capital:

$$
\frac{d w}{d x}=\frac{\partial w}{\partial t} \cdot \frac{d T}{d x}+\frac{\partial w}{\partial x}
$$

The standard wage function has an upward sloping and concave experience profile (the concavity is more pronounced when $w=\log$ wage) in cross sections and in longitudinal data. ${ }^{18}$ Its slope has been derived in human capital theory and in econometric studies. In view of (2a) it is incorrect to interpret the coefficients of experience $\frac{d w}{d x}$ as measures of returns to general human capital stocks. Such returns are measured by $\frac{\partial w}{\partial x}$ that is by coefficients of experience, when tenure is included in the wage function. Clearly $\frac{d w}{d x}$ overstates $\frac{\partial w}{\partial x}$ if specific capital 
is of any importance. The experience coefficients in the earnings function which omits tenure is an upward biased measure of returns to general human capital accumulated on the job.

It is interesting to note according to $(2 \mathrm{a})$, that even if no general capital were accumulated in the work career, wages would still rise over the life-cycle and, as a group average, the wage profile would tend to be concare so long as the tenure wage profile is concave- and $\frac{d T}{d x}$ does not increase over the iffe cycle. Wage functions with tenure variables $w(X, T)$ can be estimated in homogeneous groups without bias (homegeneity defined as the same tenure wage profile), but no such groups can be deflned a priori: In the presence of heterogeneity the tenure coefficient is likely to be exaggerated, as in the case of mobility, and corrections need to be devised. wore precisely, the bias arises because greater specificity produces larger discrepancies between the marginal product in the firm and the opportantty wage $\Delta=$ WP $-w_{g}=w_{g}+w_{e}$, where $w_{s}$ is the specific return to the worker, and $w_{e}$ to the employer, and $\Delta$ as well as $W_{s}$ differ among workers and firms. $\Delta$ affects the length of tenure. It is plausible for $w_{s}$ and $w_{e}$ to be positively correlated, because a fruttul match has to be recognized as such by both parties. Therefore $w_{g}$ is a good index of $\Delta$ and the tenure-wage coefficient which attempts to measure $\omega_{s}$ is Iikely to be correlated with expected tenure. ${ }^{19}$ Heterogeneity in $w_{S}$ is thus likely to produce an upward blas in the estinates of tenure effects on wages, that is of returns to specific worker investments. An additional source of bias could result from a positive correlation between general and specific 
investments: Here steeper tenure-wage curves would start at higher levels. To the extent that general returns to capital $\left(W_{g}\right)$ are not fully measured (standardized) by regression variables, the bias will arise. Of course, positive terure coefficients need not reflect wage growth in the firm. Higher wage levels (not growing with tenure) for the same labor in some firms create incentives to stay there longer. Although transitional, this relation is likely to be widespread in a dynamic economy as an equilbrating phenomenon. Such supply adjustments to shifting demands are most likely to involve younger people whose mobility is less costly especially in terms of specific capital losses. Note, that in this case prior mobility is not a good index of wage heterogeneity. Similarx and more long-lasting effects can be created by above equilibrium union wages and nepotism.

Can information on prior mobility be used in the wage function as an index of relevant heterogeneity, that is of individual differences in $W_{s}$ and consequently in the wage-tenure coefficient? The answer is less clear in the wage equation than in the mobility equation. Positive serial correlation in mobility makes the link between length of tenure and mobility almost definitional whatever the source of heterogeneity in mobility. The problem for the wage equation is that bias in the tenure coefficient is only in part due to heterogeneity in specific capital and the latter is responsible for only a part of the heterogeneity in mobility. Thus prior mobility may be a weak instrument for elimination of heterogeneity bias. Its role in wage formation is nevertheless of interest to our study. 
and

Table 6 presents wage functions of the younger $n$ older NLS men, and of all men in MID. The independent variables are the same as in the mobility functions in Table 5. The dependent variable is the logarithmic wage, and row (1) is the "standard" wage function where the independent variables are education and experience. In the next row the tenure terms are added. In the third row we add the prior mobility variable and in the last row we observe its interaction with experience.

In the young men's panel the introduction of tenure reduces the experience coefficient: At this stage (on average five years of experience), wages grow 6.6 percent per year of experience (lst row of Table 6); wages grow 4.3 percent as returns to general post-school human capital accumulation (2nd row of Table 6) and 2.3 percent due to specific capital accumulation. The tenure coefficients are large and significant. Prior mobility is not related to current wages and does not affect the tenure coefficients. The coefficient of the interaction variable is surprisingly positive but quite small, and its introduction raises the tenure coefficient slightly. Apparently differences in early mobility of young men are not indicative of future differences in specific capital investments nor do they capture differences in wage levels which are positively related to the length of current tenure.

In the wage function for NLS older men the experience profile is a plateau, but tenure slopes are positive (and concave) though much flatter than for young men. 21 still, the observed tenure effect is biased upward. Introduction of prior mobility cuts the linear term in half and reduces its significance. We may conclude that repeated mobility at an advanced stage of the life-cycle is an indicator of persistent turnover, denoting little investment in specific capital. The mobility variable 


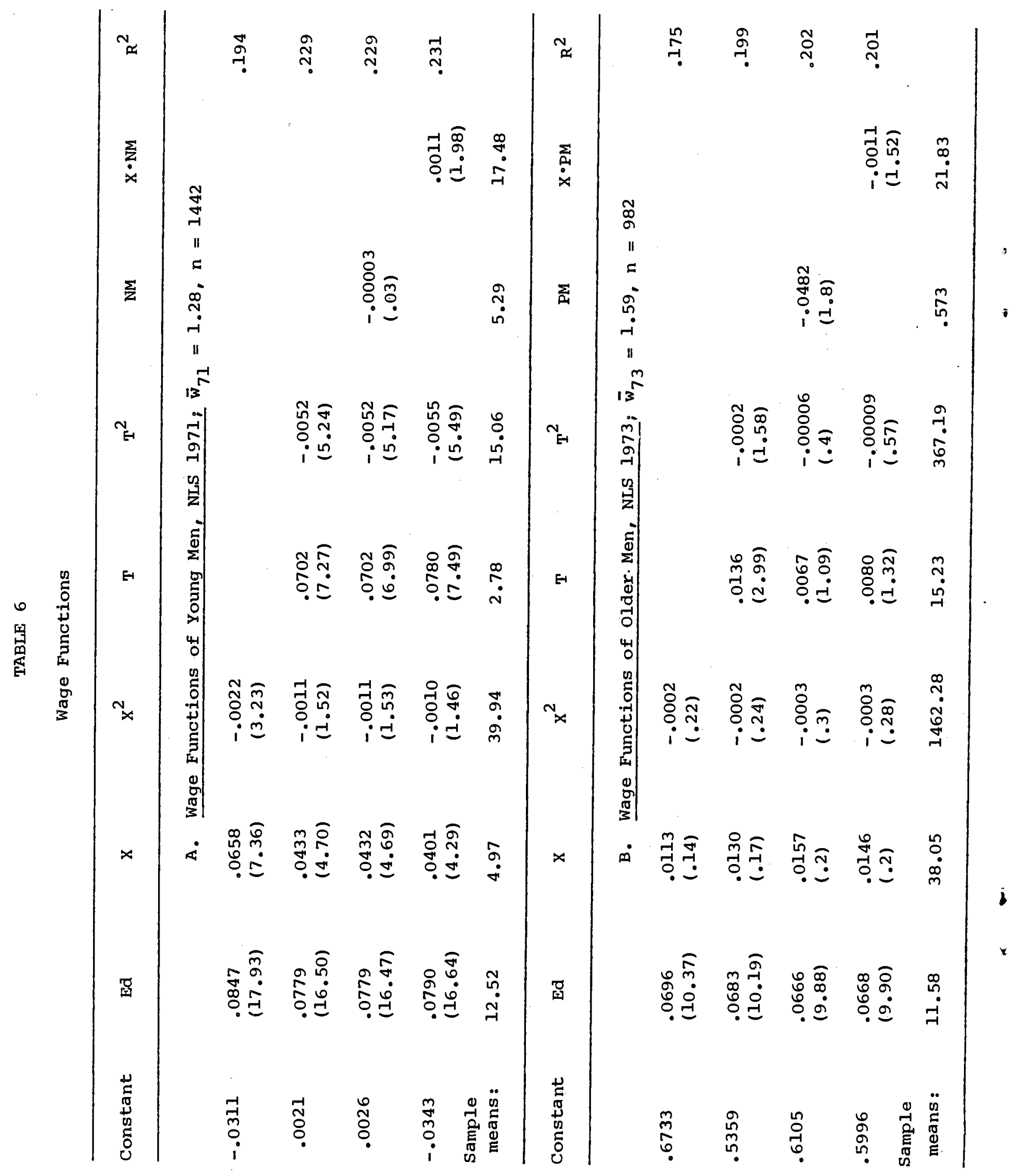




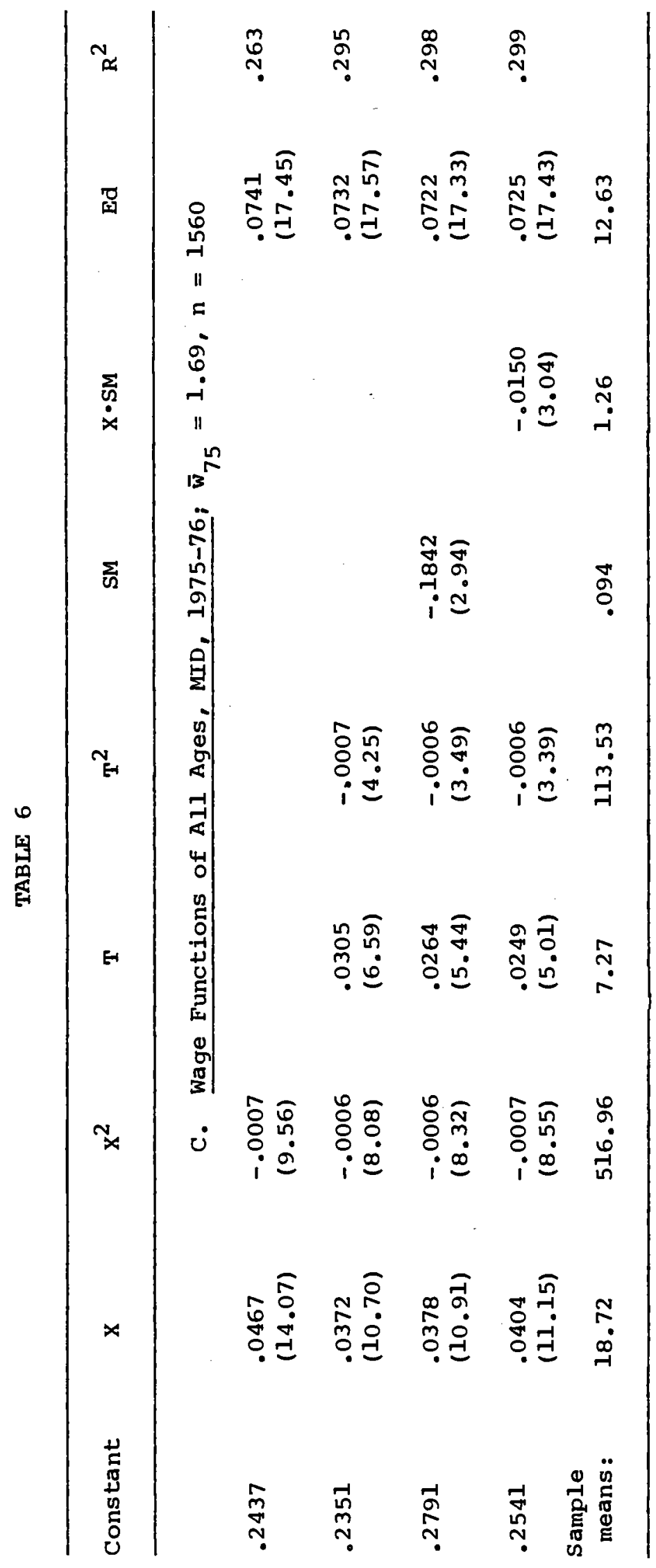


has a negative effect, showing that

frequent movers have lower wages than stayers, given education. experlence, and current tenure. Mis is in contrast to the young whose past mobillty did not imply a downard selection. We may conclude that intensive early mobility-about a half of the first decade in our Nus data-is not necessarily an Lnverse index of longer-run tendencies to acquire specific capital or an index of inability to acquire a good job match. It may even be a positive index of efficiency in wage gains by woving across firms or of greater intensity of search for an optimal career.

Taken together the findings in both NLS panels show that tenure effects on wages are significant, reflecting the firm-specific component of wage progress on the job. This component accounts for about. one third of wage growth per year in the early part of working life. At young ages, past mobility does not clearly distinguish tendencies toward firm specific human capital behavior. It does so, however, at older ages. At that stage lesser specific investments also result in lower wages, apparently as a result of slower growth over the past decades. 22

The wage function in the MID panel, which covers all working ages, indicates that on average (and in mid-career) the firm specific component accounts for 20-25 percent of wage growth per year (difference between the X-coefficients in lines 1 and 2, panel c). Prior mobility is negatively related to wages. The interaction term is also negative suggesting that men who cortinue to be frequent movers in the third decade of their working lives have both lower wages and flatter experience profiles of wages. The inclusion of prior mobility variables reduces the tenure slope by close to 20 percent. Thus, heterogeneity biases the tenurewage slope coefficient upward by about 25 percent, half as much as it biased the tenure-mobility slope (panel C of Table 5). 
7. Tenure, Experience and Mobility: Additional Remarks

We used the generalized term "specific human capital behavior" to cover both the informational theory of job matching and the theory of specific human capital investment. The former is a necessary condition for the latter, and both are required for completeness.

There is another and popular view that the reallty of tenure effects on mobility and on wages is largely institutional. The effects we analyzed are seen as "seniority rlghts" which include job security, pension rights, vacations, and seniorlty based pay and promotion advantages. But the distinction is superficial. The "rights" themselves may well dertve from human capital specificlties in the presence or absence of formal, especially union, regulations. Indeed, recent research shows that tenure turnover profiles decllse and tenure wage profiles grow as much and more (!) in the non-union as in the union sector. 23

In the past, experience coefficients $\frac{d w}{d x}$ were often crudely interpreted as on-the-job general investments. In the wage function which includes tenure the experience coefficients $\frac{\partial w}{\partial x}$ effectively segregate returns to general human capital investnents, but they contald both returns to on-the-job general investment and across jobs wage gains due to mobility (but not to tenure). These across-jabs wage changes are positive in purposive quits especially in migration, but are often . negative when job change results from layoff, "exogenous" quit, and job dissatisfaction. 24 
Over the life-cycle the effects of mobility on wages become increasingly less favorable at least as measured by money wages. Quits, migration, and occupational upgrading predominate in mobility of the young, but they become relatively unimportant at older ages. Since the frequency of job change declines over the life cycle for reasons already spelled out, the mobility component of wage growth declines over the life cycle both as a result of declines in the size and in the frequency of wage gains across firms. This is another aspect of the well-known concavity of the experience profile of wages.

Some models elevate the across-firm wage change to a single explanation of the typical concave life-cycle wage profile: The worker is envisaged as moving up a fixed wage offer distribution over his lifetime. Successful on-the-job search results in off-the-job wage growth. With a fixed wage offer distribution turnover declines with labor market experience. Thus older workers have a higher wage and a smaller probability of future separation. 25

Although they produce concavity in the wage profiles, such models are quite inadequate as major explanations of magnitudes of wage growth over the life cycle $\left(\frac{d w}{d x}\right)$ : In a calculation based on the colemanRossi data Bartel (1975) shows that no more than 25 percent of personal wage growth can be attributed, to across-firms wage changes during the flest 15 years of work experlence, when mobility is most pronounced. The models, therefore, neglect the bulk of the phenomenon they are ering to explais. Moreover, concavity in the wage profile does not require job mobility, in human capital theory, or in fact: Borjas (1975) found the typically pronounced concavity in wage profiles of sts workers who spent all of theit working life in a single firal. 
Although crude, our estimates of temure and experience wage effects suggest that about 25 percent of life-cycle wage growth, which abstracts from economy-wide changes, is due to specific capital investment. Taken together, the estimates provice a complete though very rough decomposition of life-time wage growih: About 25 percent of it is due to interfin mobility, another, 25 percent to firm specific experience, and over. 50 percent is due to general (transferable) experience.

Perhaps the best way to summarlze the life-cycile relation between mobility and wages is to recogrize that injtial (flrst decade ?) job seareh has two major purposes: to gain experience, wages, and skills by moving across fins, and to fide, sooner or later, a suitable job is which one can settie for a long the. The iffe-cycle decline is mobility is, in part, eqidence of successful infetal mobility, which is corcoborated by corresponding life-cyele growth in wages.

In both age grows, stayers and successful searchers grow saster than unsuccessful searchers or "non-investing" novers, However, a cconparison of movers and stayers puts successtul searchers in the category of movers among the yourg, but is the category of stayers (they moved when younger) among the old. As a result, comarisons of stayers and movers show that young movers do as well or better than stayers, but ulcimate stayers show superior wage growth and higher wage levels in the later decades. 


\section{FOOTNOTES}

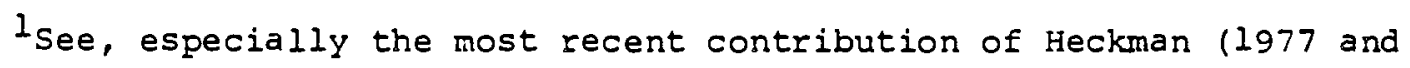
1978), and Jovanovic (1978). Recent work of sociologists, including their own, is reviewed by Singer and Spilerman (1976).

essay
2 This $\wedge$ serves as a partial analytical underpinning for an ongoing NBER study of Lifetime Earnings and Labor Mobility carried out by Bartel, Borjas, and Mincer. (Some of the ideas developed in this essay are pursued formally in a more specialized focus by B. Jovanovic in this volume and elsewhere.)

3 The subject of women's labor mobility is reserved for separate study.

${ }^{4}$ For analysis of geographic mobility see Bartel (1978) and Mincer (1978).

5 BLS, Special Labor Force Report No. 35, "Job Mobility in 1961", Table A.

${ }^{6}$ This is in contrast to the BLS data of Table 1 and may be peculiar to the NLS sample. 
${ }^{7}$ In his work, Jobanovic (1978) has shown that job matching processes produce downward sloping tenure separation functions and upward sloping tenure-wage functions. Investments of employers and workers in their mutual association are a corollary. We use the language of specific capital to cover the combined phenomena.

8 For a theoretical treatment of this distinction see Mortensen (1978)

9 We may note that even if returns to specific capital accumulation, and in particular $w_{s}$ did not decelerate with tenure, but grew in a linear fashion, the resulting growth of acceptance wages would nevertheless lead to decelerating declines in the probability of quit, given a declining upper tail of the wage offer distribution.

10 We must be careful, however, not to assert the converse: by itself, inertia does not bring about specific investments.

${ }^{11}$ For evidence and references see J. Mincer (1974).

12The deterministic treatment is for expository convenience only. See Part II for a more formal and more specialized analysis of the stochastic process.

${ }^{13}$ Perhaps a simple way of illustrating the conclusion that $\frac{d T}{d x}$ is larger with than without tenure dependence, is to consider a case in which we go from none to some tenure dependence. Let the mean tenure in the group be $\bar{T}$ and the overall turnover rate $s$. Then after a passage of a year the (1-s) stayers have increased tenure by one year, while the $s$ movers, without tenure dependence, lost, on average $\bar{T}$ years of tenure. The net change $\frac{d T}{d x}$ is therefore (1-s) - ST, which approaches 
zero since $T$ approaches $\left(\frac{1}{s}-1\right)$. Now, let $s$ remain the same, but the process become tenure-dependent. In this case, the average tenure lost by movers is $\overline{\mathrm{T}}_{\mathrm{m}}<\overline{\mathrm{T}}$ since proportionately more of them are drawn from low tenure classes. Consequently the net gain in tenure $\frac{d T}{d x}=(1-s)-$ $s T_{m}>(1-s)-s T$.

${ }^{14}$ Theorem 2, Part II.

${ }^{15} \mathrm{Cf}$. Theorem 3 in Part II. Such a decline in the variance need not be inconsistent with a widening of differences in mobility rates.

${ }^{16}$ The best known work is that of Blumen, Kogan, and Mccarthy (1955). For a recent exposition and critique see Singer and Spilenman (1976).

${ }^{17}$ For those men whose current tenure started before the initial year of reported prior mobility (1965 for the old NLS, 1966 for the young NIS, and 1968 for MID), no information on PM is available (12\% of young NLS, 62\% of the old NLS, and about 50\% in MID). As a check on the results in Table 5 which implicitly assigns values PM = 0 to those whose tenure is too long, we used dummy variables on the complete samples, and we also replicated the regressions of Table 5 on the subsamples which contained information on prior mobility. The results were quite similar to those in Table 5 with one interesting feature that was already mentioned: The tenure coefficients for the old men in NLS (with short tenure in the subsample) were as steep as for the young and the inclusion of PM reduced the slope by a relatively small amount as it did for the young.

${ }^{18}$ The longitudinal evidence is less familiar. See Borjas and Mincer (1978) reporting Coleman-Rossi data, and Anderson, Balcer, and Diamond (1976) on the Continuous Work History Sample. 
19

Cf. discussion in Part II, following Theorem 3.

${ }^{20}$ Dollar wage equations, not shown here, show similar patterns, but weaker predictive power.

${ }^{21}$ This is true also in the sample with $T \leq 8$, in contrast to the short-tenure mobility equation (see note 17).

${ }^{22}$ Supporting evidence is shown in the Bartel and Borjas paper in this volume, as well as in previous research by Borjas. Borjas (1975) classified the older NLS men into movers and stayers. The latter were defined by the fact that their current job was the longest ever. Education and experience were only slightly different in the two groups. The movers had lower wages (about 25 percent) and flatter experience profiles.

23Freeman (1978), Borjas (1978), and others. The flatter union tenure slopes have been analyzed as effects of union policy. We suggest that they may also reflect lesser heterogeneity in the union compared to the non-union sector.

${ }^{24}$ See Bartel and Borjas, this volume.

${ }^{25}$ Burdett (1973), Sorensen (1974). Jovanovic (1978a) is an adaptation of Burdett, which allows for on-the-job human capital accumulation. It is doubtful, however, that the assumption of a fixed wage offer distribution can be maintained for workers whose skills are growing and changing over the life-cycle. 
Labor Mobility as a Stochastic Process

In this part we treat labor mobility and wage growth over the life cycle as related stochastic processes. We first focus on the evolution of these processes for a given worker, and we interpret our formulation within the context of existing theories of turnover and of wage growth and list some of the implications of these theories. Next we take up the question of unmeasured heterogeneity in the population, and the problem of sample selection over time,known as the "mover stayer" problem. $\Lambda$ remarkably simple result is proved in Theorem 3 which relates the behavior of a heterogeneous group to the behavior of the individual members of that group. In interpreting the result, we pay particular attention to the on-the-job training hypothesis. Lastly, we describe an estimation method which may be applied to estimete various parametrizations of the separations and wage equations. 
Defialtions:

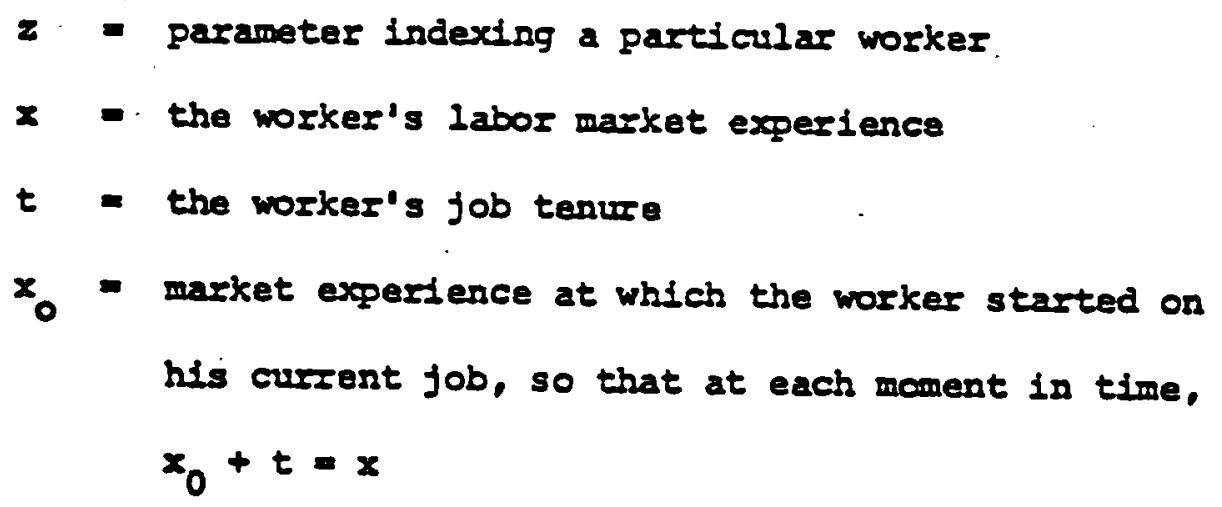

Let

$$
\begin{aligned}
F\left(t \mid x_{0}, z\right) \equiv & \text { Probability that for a worker of type } z, \\
& \text { job tenure does not exceed } t \text { on a job which } \\
& \text { started at } x_{0}
\end{aligned}
$$

Let $f\left(t \mid x_{0}, z\right)=\partial F / \partial t$ be the assoclated density, and let $\hat{s}\left(t, x_{0}, z\right)$ be the "harard function" of this distribution, defined by $\hat{g}=t /(I-F)$. Then $\hat{s}$ is the conditional density of job separation at tenure $t$, given that a tenure level $t$ has been attadned. The definitions of $i s$ and $f$ imply that $F$ may be written as

$$
\left.F\left(t \mid x_{0}, z\right)=1-\exp l-\int_{0}^{t} \hat{s}\left(y, x_{0}, z\right) d y\right]
$$

The development thus far is perfectly general. There may be a positive probabilfty that a job-episode never terminates, in whtch case 


$$
\lim _{t \rightarrow \infty} F\left(t \mid x_{0}, z\right)<1,1 . e ., \int_{0}^{\infty} s\left(y, x_{0}, z\right) d y<-
$$

It should be noted that $F$ determines $\hat{s}$ uniquely and vice versa. Since $E \geq 0, \hat{s} \geq 0$ so that $F$ is son-decreasing.

One purpose of this section is to draw some parallels between wage rates and separation probabilities. Let $\dot{w}\left(t, x_{0}, z\right)$ be the mathe-

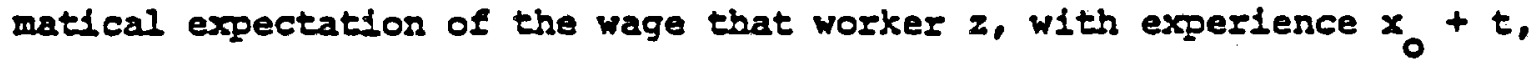
and tenure $t$ will receive. It may be noted that both $\dot{w}$ and $\dot{s}$ are mathematical expectations conditional upon $t_{1} x_{0^{\prime}}$ and $z$.

Hereafter it is assumed that when a particular fob episode terminates, it is imedately followed by a new job episode. That is, there are assumed to be no unemployment spells or spells of market nonparticipation. Given this assumtion, consider now the special case in which $\partial \hat{s} / \partial x_{0}=\partial F / \partial x_{0}=0$. Then each jab episode is identically distributed. If, in addition, the job episodes are also assume to be Independently as well as identically distributed, then turnover becomes a pure renewal process [see Feller (1966) Ch. 11]. In what follows, we study processes that are more general than the renewal process, and more general than semi-Markov processes.

Let $a(x, z)$ be the probability density that worker $z$ will experience a fob-separation at the point in time at which his market experfence is equal to $x$. (For the special case where turnover is a renewal process, $a(x, z)$ is ksown as the renewal density.) Also let $h(t \mid x, z)$ be the probability density that a worker with market experience $x$ will have current job tenure equal to $t$. Note that for this statement to be 
true, the worker must have experienced a fob separation at exactly $x$ - $t$ level of market experience, and no subsequent separations. Therefore, (4) $h(t \mid x, z)=\left\{\begin{array}{l}1-F(x \mid 0, z) \text { if } t=x \\ a(x-t, z)[1-F(t \mid x-t, z)] \text { if } 0 \leq t<x \\ \text {. }\end{array}\right.$ Then

$$
\begin{aligned}
a(x, z)= & \dot{s}(x, 0, z)[1-F(x \mid 0, z)]+\int_{0}^{x} \dot{s}(t, x-t, z) b(t \mid x, z) d t \\
= & i(x, 0, z)[1-F(x \mid 0, z)]+\int_{0}^{x} \hat{s}(t, x-t, z) a(x-t, z) \\
& {[1-F(t \mid x-t, z)] d t }
\end{aligned}
$$

Define $y(x, z)$ as the mathematical expectation of worker $z$ 's wage conditioned only on his market experience. Then

$$
\begin{aligned}
y(x, z)= & \dot{w}(x, 0, z)[1-F(x \mid 0, z)]+\int_{0}^{x} \dot{w}(t, x-t, z) \\
& a(x-t, z)[1-F(t \mid x-t, z)] d t
\end{aligned}
$$

Now define two new functions

$$
s(t, x, z)=\hat{s}(t, x-t, z) \rightarrow s_{x}=\dot{s}_{x_{0}} \text { and } s_{t}=\hat{s}_{t}-\hat{s}_{x_{0}}
$$

and

$$
w(t, x, z)=\hat{w}(t, x-t, z) \rightarrow w_{x}=\hat{w}_{x_{0}} \text { and } w_{t}-\dot{w}_{t}-\hat{w}_{x_{0}}
$$

(where subscripts denote partial derivatives). 
Making the substitution into (5) and (6).

$$
\begin{aligned}
a(x, z)= & s(x, x, z)[1-F(x \mid 0, z)]+\int_{0}^{x} s(t, x, z) \\
& a(x-t, z)[1-F(t \mid x-t, z)] d t
\end{aligned}
$$

and

$$
\begin{aligned}
y(x, z)= & w(x, x, z)[1-F(x \mid 0, z)]+\int_{0}^{x} w(t, x, z) \\
& a(x-t, z)[1-F(t \mid x-t, z)] d t
\end{aligned}
$$

There are several reasons for choosing this approach. First, the determintstic earnings-function approach [see, for example, kincer (1974) I is a special case of the above formulation. In the earnings function approach turnover is not considered expldcitly so that job-tenure is not included in the regressions. Such regression equations are here interpreted as expectations conditional on $x$ and on the measured component of $z$, and the expression that characterize such conditional expectations are provided in equations (8) and (11). A set of sufficient conditions under which the conditional expectation of the wage is a monotonically increasing function of experience is provided below.

Second, the job-matching theory of turnover as developed in Jovanovic ( 1978 ) is fully consistent with the above formulation when the latter is restricted to $s_{x}=w_{x}=0$ for all $(x, t, z)$ so that the turnover process is predicted by the theory to be one of pure renewal. The key assuptions in generating such a result are a constant rate of discount, and infinite horizon, and an assumption about the job-search 
process that makes the latter "pure experience search" in the terminology of Nelson (1970). The model also implies $w_{t}>0$ for all $t$, and $s_{t}<0$ for large enough $t$ and perhaps for all $t$.

Two other search models that explicttly look at the Implications for Ife cycle mobility are those of Burdett (1973) and of Jovanovic (1978a). Both models Lrvolve the worker moving up a fixed wage-offer astribution over their 1ifetime, with search of the "pure search" kind (Nelson's terminology again). Both models imply that in the absence of on-the-job training, $s_{x}<0$ and $w_{x}>0$ while $s_{t}=w_{t}=0$ for given $x$. When firm-specific human capital imvestment is introduced IJovanovic (1978a) J, the latter prediction changes to $s_{t}<0$ and $w_{t}>0$ for all workers except the very old for whom $s_{t}>0$ and $w_{t}<0$ as they allow their human capital to deprectate toward the end of their iffetime. General on-the-job training raises wages, implying $w_{x}>0$ given a monotonic increase in general training over time. Since general trainding raises the worker's productivity in many firms, it is not expected to affect turnover, and therefore $s_{x}=0$ is consistent with $w_{x}>0$ and with the presence of general training. A somewhat different argument asserts that the presence of general tratining is the cause of turnover at younger ages, because it may be optimal for the training to be acquired in several different flrms and such turnovier is planned in advence. To the extent that such turnover is significant, (and Ittele evidence is avatiable to support its significance), it may produce non-monotonic effects on $s(t, x, z)$ for young workers as $t$ and $x$ Increase. 
Next, define

(9)

$$
B(t, x, z) \equiv \int_{0}^{t} h(\tau \mid x, z) d \tau \geq 0
$$

so that $H(0, x, z)=0$ and $H(x, x, z)=F(x \mid 0, z)$. Then integrating by parts in (7) and (8) one obtains

$$
a(x, z)=s(x, x, z)-\int_{0}^{x} s_{t}(t, x, z) \quad \forall(t, x, z) d t
$$

and

$$
y(x, z)=w(x, x, z)-\int_{0}^{x} w_{t}(t, x z) H(t, x, z) d t
$$

Equations (10) and (11) should be compared for their identical structure. The following results follow drectly from equations (10) and (11), and are presented in Theorem 1:

Theorem I: Let $s_{t}<0$ and $w_{t}>0$ for all values of the arguments. Then

$$
\begin{aligned}
& a(0, z)=s(0,0, z), y(0, z)=w(0,0, z) \\
& a_{x}(0, z)=s_{x}(0,0, z)+s_{t}(0,0, z), \\
& y_{x}(0, z)=w_{x}(0,0, z)+w_{t}(0,0, z)
\end{aligned}
$$

and for any $x>0, a(x, z)>s(x, x, z)$ and

$$
y(x, z)<w(x, x, z)
$$


Proof: The assertions follow from the observation that

$$
H(t, x, z)>0 \text { for any } t>0 \text {, and from } H(0,0, z)=0 \text {. }
$$

Next, consider the special case in which $s_{x}=0$, as would be true if turnover was a pure renewal process. We then have the following theorem:

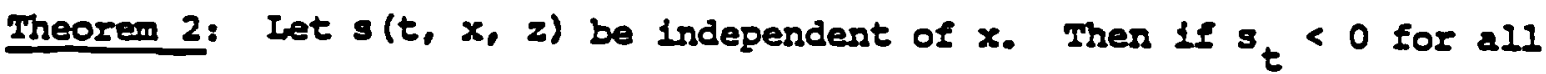
$(x, t, z)$ then $a_{x}<0$ for all $(x, z)$.

Proof: Differentiating with respect to $x$ in equation (10) and applying the assumption that $s_{x}=0$, yields

$$
\begin{aligned}
a_{x}(x, z)= & s_{t}(x, x, z)[1-P(x, 0, z)]-\int_{0}^{x} s_{t}(t, x, z) \\
& B_{x}(t, x, z) d t
\end{aligned}
$$

and since, by assumption, $s_{t}<0$, it is sufficlent to prove that $H_{x}<0$. for all $(t, x, z)$. But since $s$ does not depend on $x$, neither does $F$. Therefore, $H_{x}(t, x, z)=\int_{0} a_{x}(x-y, z)[1-P(y \mid x-y, z)] d y$. Therefore, $b_{x}(t, x, z)<0$ if $a_{x}(x-y, z)<0$ for all $y \in(0, x)$. But then, $a_{x}(x, z)<0$ for all $x$ if there exists an $\varepsilon>0$ no matter how small such that $a_{x}(x, z)<0$ for $x \varepsilon(0, \varepsilon)$. But such an $\varepsilon$ must exist if $a_{x}(x, z)$ is continuous at zero, because by Theorem 1 . $a_{x}(0, z)=s_{t}(0,0, z)+s_{x}(0,0, z)<0$. (The last Ineorality follows by the assumptions of the theorem.) This completes the proof of the theorem. 
Intuitively, one expects that Theorem 2 should extend to the case where $s_{t}<0$ and $s_{x}<0$, that is, to the case where the separation propensity declines with both tenure and market experience, and that the decline in the separation propensity considered as a function of market experience alone $[a(x, z)]$, should, if anything, be reinforced. mile this conjecture may be true, an attemot at proving it along the inses of the proof of Theorem 2 fails, because $H_{x}$ can not be signed.

Theorem 2 asserts that the renewal density declines monotonically If the inter-event waiting-time distribution possesses a monotonically decreasing hazard rate. Note that a parallel result for monotonically Increasing hazard rate distribution does not bold. That is, $s_{t}>0$ everywhere does not imply that $a_{X}>0$ for all $x$, and an attempt at a proof along the lines of the proof of Theorem 2 is quickly seen to fall [and a counterexample is given in Brown (1940)]

It should be noted that $y(x, z)$ is the wage-experience profile for a homogeneous group of type $z$. By differentiating in equation (8), conditions may be derived under which the wage experience profile will be increasing and concave $\left(y_{x}>0, y_{x x}<0\right)$ for each homogeneous group. These conditions involve restrictions on both $w(t, x, z)$ and on $s(t, x, z)$. Por example, one set of sufficient conditions for a monotonically lacreasing wage-experience profile $\left(y_{x}>0\right)$ is: $s_{x}=0$, $s_{t}<0, w_{t}>0, w_{x}>0$ and $w_{t x}>0$, as may be verified by direct dffere entiation in (8) (and by applying the result of Theorem 2 which states that $s_{t}<0$ and $s_{x}=0$ jointly imply $a_{x}<0$ everywhere). Assuming, that $s_{x}=0$, is theoretically consistent with assuming that $w_{x}>0$-the accumulation of purely general on-the-job training raises the worker's 
Productivity in all fires by an equal amount, and it raises his wage (hence $w_{x}>0$ ) but is not expected to have any effect on his separation propensity (hence $s_{X}=0$ ). Sufflcient conditions for concavity of the wage-experience profile may also be derfied but turn out to be much more complicated.

Let $I(x, z)$ be the mathematical expectation of current tenure. The latter is distributed according to (4), and therefore,

$$
T(x, z)=x[1-F(x \mid 0, z)]+\int_{0}^{x} t h(t \mid x, z) d t=x-\int_{0}^{x} y(t, z, z) d t
$$

The second equality follows after integration by parts. Since $B>0$, $T(x, z)$ can not exceed $x$. Differentiating with respect to $x$,

$$
I_{x}(x, z)=1-F(x \mid 0, z)-\int_{0}^{x} H_{x}(t, x, z) d t
$$

so that $T_{x}(0,2)=1$. If turnover is a pure renewal process with $s_{t}<0$ everywhere, then from Theorem $2, H_{x}>0$, and $T_{x}>0$ for all $x_{1}$ in other words, the average current job tenure will always be increasing for a cohort of workers as their market experience increases under these assumptions.

Let $t_{1}, t_{2}, \ldots$ be the sequence of completed job durations. Then the distribution function for the length of the $n^{\text {th }}$ job eplsode is n-1

$F\left(\left.t_{n}\right|_{j=1} ^{n-1} t_{j}, z\right)$. The $t_{j}$ are therefore neither independent nor 1dentically distributed random varlables so long as the aging effect, $s_{x}$ is not zero. If there is no aging effect, then each job-episode has 
the same distribution, and if, in addition, one assumes that the jobepisode durations are independently distributed, then turnover is a pure renewal process. Let $n(x, z)$ be the number of fob changes (the number of completed episodes or the number of "prior moves") on the experience interval $(0, x)$. Then

$$
E n(x, z)=\int_{0}^{x} a(t, z) d t
$$

To see this, note that $a(x, z) \Delta x+0\left[(\Delta x)^{2}\right]$ is the probability that exactly one job change will occur on the Literval $(x, x+\Delta x)$. The expression in equation (25) is the sum of these probabilities over such disfoint intervals as $\Delta t$ tends to zero. Dividing both sides of (14) through by $x$, taking the limit as $x$ tends to infinity and applying I'Hopital's sule, one obtains

$$
\lim _{x \rightarrow \infty} a(x, z)=\lim _{x \rightarrow \infty} \frac{E n(x, z)}{x}
$$

of course, $\frac{\partial}{\partial x}[E n(x, z)]=a(x, z)$, and $\frac{\partial^{2}}{\partial x^{2}}[E n(x, z)]=a_{x}(x, z)$. Therefore, a monotonically decreasing experience profile of turmover implies concavity of the expected number of moves treated as a function of experience.

\section{Examole: a pure renewal process:}

Let $F$ be the mixed exponential distribution:

$$
F(t \mid x, z)=1-\frac{1}{2}\left[e^{-2 t}+e^{-(z+b) t}\right]
$$


$-12-$

so that no aging effects exist. Then

$$
f(t \mid x, z)=\frac{1}{2}\left[2 e^{-z t}+(z+b) e^{-(z+b) t}\right]
$$

and

$$
\begin{aligned}
& a(t, x, z)=z+\frac{b}{1+e^{b t}} \\
& s_{t}(t, x, z)=-\frac{b^{2} e^{b t}}{\left(1+e^{b t}\right)^{2}}
\end{aligned}
$$

The slope of the separation function is in this case independent of $z$. If $b=0, s_{t}=0$ and so $b$ is a parameter denoting the extent of duration dependence. Then let

$$
\hat{T}(x, z)=\frac{1}{2}\left(\frac{1}{z}+\frac{1}{z+b}\right)<\frac{1}{z}
$$

The renewal equation (5) has for this case explicitly been solved by Bartholomew (1972) to yield

$$
\begin{aligned}
a(x, z) & =[\hat{T}(x, z)]^{-1}+\left[z+\frac{b}{2}-[\hat{T}(x, z)]^{-1}\right) e^{-\left(z+\frac{b}{2}\right) x} \\
& =\frac{2(z+b) z}{2 z+b}-\frac{b^{2}}{2(2 z+b)} e^{-\left(z+\frac{b}{2}\right) x}
\end{aligned}
$$

so that

$$
a_{x}(x, z)=-\frac{b^{2}}{4} e^{-\left(z+\frac{b}{2}\right) x}
$$


If there is no duration dependence with tenure $(b=0)$, then separations also do not decline when considered as a function of age. Notlce also that

$$
a_{x z}(x, z)=-x a_{x}(x, z)>0
$$

so that although the $s(t, x, z)$ curves are paraliel in $z,\left(s_{t z}=0\right)$, the age curres are not-they diverge. The relationship between the tenure and age curves is depicted in the figure below:

SEPARATIONS

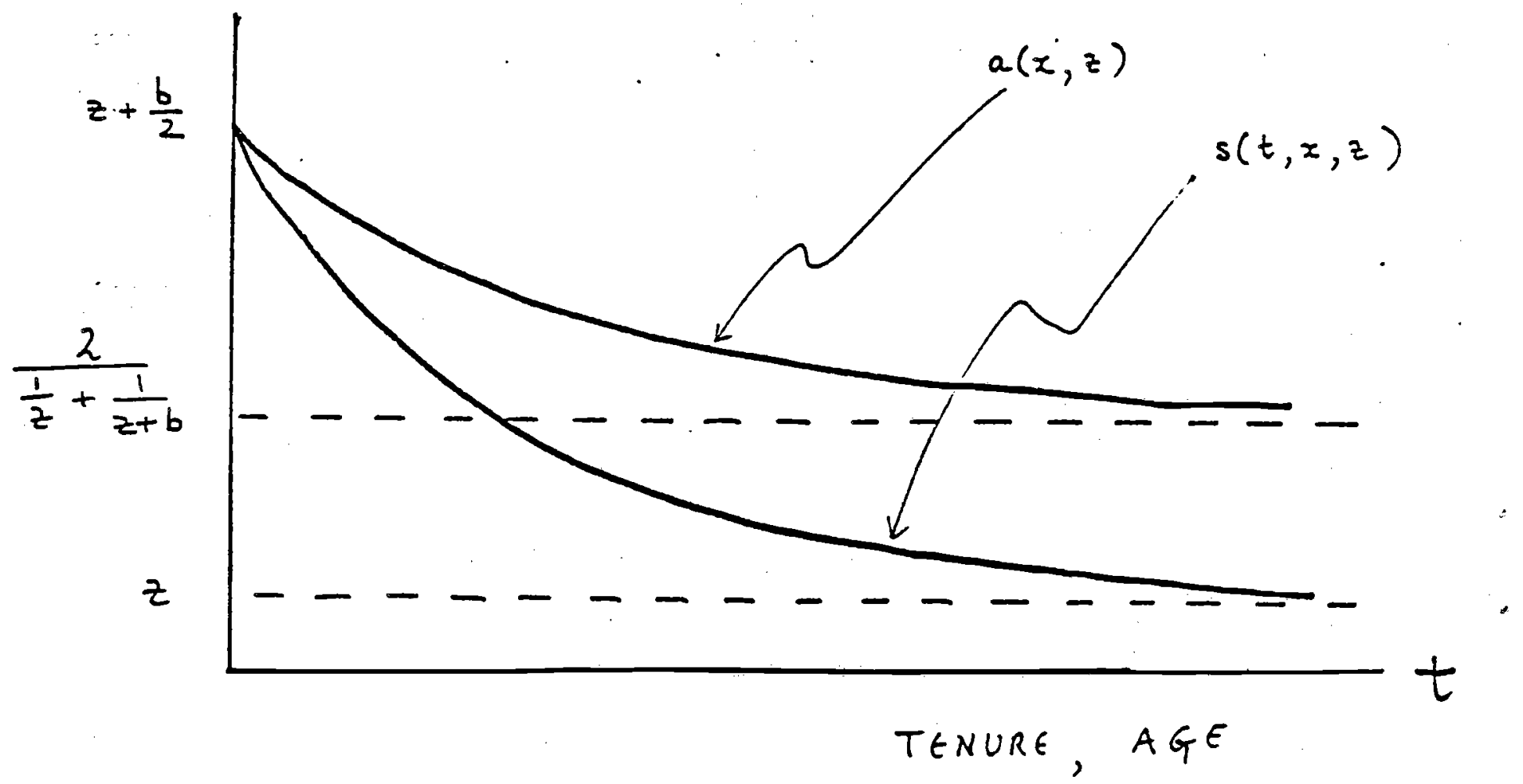


The divergence of age profiles therefore can be explained not only by divergences in levels of speciflc human capltal (as argued in Part I of this paper) but also as a purely statistical phencmenon.

In this case, convexity of $s(t, x, z)$ in $t$ implies convexity of $a(x, z)$ in $x$. As $b$ (the duration-dependence parameter tends to zero, both $a(z, z)$ and $s(t, x, z)$ tend to a constant, $z$.

\section{Group Relationships}

The Individual-speciflc parameter $z$ is by assumption unobservable. It is an "Incldental parameter." The population distribution of $z$ is assumed to be $p(z)$ with mean $\psi$ and varlance $\sigma^{2}$. The non-degeneracy of this afstribution gives rise to the dynamic version of the sampleselection problem studied below.

upan enterling the labor market, a worker is assumed to be a randow drawing erom the distribution $p(z)$. On the other hand, a worker who is starting out on a fob other than his flrst, at a market-experlence level $x>0$, is not representative of the entire population in the sense that he can not be considered a random drawing from the alstribution $p(z)$. Although $p(z)$ is interpreted to be an unmeasured personal characteristic, it is likely to be correlated with measured personal characteristics such as years of schooling, race, sex and so on. The unmeasured variablifty in separation propensities decreases as the number of personal characteristics held constant increases, which is another way of saying that part of the variance of $z$ is "explained" by the variance of a set of personal characteristics. (Note that this is quite diferent from the statement that the varlance of the conditional 
distribution is never greater than the varlance of the marginal distribution. The latter statement is false.)

The objective now is to characterize the distribution of $z$ conditional upon $x$ and $t$. Let $p(z \mid x)$ be the distribution of $z$ which applies to workers who are just starting a new job at experience level $x$. Applying Bayes' Theorem,

$$
p(z \mid x)=\left\{\begin{array}{cc}
\frac{a(x, z) p(z)}{f a(x, z) p(z) d z} & x>0 \\
p(z) & x=0
\end{array}\right.
$$

$p(z \mid x)$ is a continuous function of $x$ except at $x=0$. (The continuity of $p(z \mid x)$ at $x>0$ follows if $a(x, z)$ is continuous.)

Now let $\dot{p}\left(z \mid x_{0}, t\right)$ be the prabability density that the worker is of type $z$ given job tenure $t$ and experience $x_{0}+t$. at the time be Joined his current firm the worker was drawn from the population $p\left(z \mid x_{0}\right)$. Applying Bayes' Theorem again.

$$
\hat{p}\left(z \mid x_{0}, t\right)=\frac{\left[1-F\left(t \mid x_{0}, z\right)\right] p\left(z \mid x_{0}\right)}{\int\left[1-F\left(t \mid x_{0}, z\right)\right] p\left(z \mid x_{0}\right) d z}
$$

Equation (16) follows because $1-F\left(t \mid x_{0}, z\right)$ is just the probability that the worker of type $z$ will attain tenure $t$ in a job which he started at experlence-level $x_{0}$.

Writing $\hat{s}\left(t \mid x_{0}, z\right)$ instead of $\hat{s}\left(t, x_{0}, z\right)$ (thereby emphasizing the nature of the conditioning), let

$$
\dot{s}\left(t, x_{0}\right) \equiv f \hat{s}\left(t \mid x_{0}, z\right) \hat{p}\left(z \mid x_{0}, t\right) d z
$$


be the probability that the worker will experience a separation at tenure $t$ given $x_{0}$ and $t$. We then have

\section{Theoren 3}

$\therefore] \quad \dot{s}_{t}\left(t, x_{0}\right)=f \hat{s}_{t}\left(t \mid x_{0}, z\right) \hat{p}\left(z \mid x_{0}, t\right) d z-\sigma^{2}\left(\hat{s} \mid x_{0}, t\right)$

(18) and

$$
\hat{w}_{t}\left(t, x_{0}\right)=\int \hat{w}_{t}\left(t \mid x_{0}, z\right) \hat{p}\left(z \mid x_{0}, t\right) d z-\operatorname{Cov}\left(\hat{s}, \hat{w}_{\mid} \mid x_{0}, t\right)
$$

where $\hat{w}\left(x_{0}, t\right)$ is the mathematical expectation of the wage given $x_{0}$ and $t$, where $\sigma^{2}\left(\hat{s} \mid x_{0}, t\right)$ is the variance of $\hat{s}\left(t \mid x_{0}, z\right)$ in the population $\hat{p}\left(z \mid x_{0}, t\right)$ and where $\operatorname{Cov}\left(\hat{s}, \hat{w} \mid x_{0}, t\right)$ is the covariance of $\hat{s}\left(t \mid x_{0}, z\right)$ and $\hat{w}\left(t \mid x_{0}, z\right)$ in the population $\hat{p}\left(z \mid x_{0}, t\right)$. Before proving this theorem, we elaborate on the meaning of its assertions. When $t$ is increased by one unit while $x_{0}$ is held constant, tenure and experience both increase by one unit. Therefore, $s_{t}$ is the sum of the tenure effect and of the pure age effect, and similarly for $w_{t}$. In words, the first assertion of the theorem may be expressed as : the slope of the average separation rate is equal to the average of the Individual slopes, minus the varlance of the separation rates in the current population $\hat{p}\left(z \mid x_{0}, t\right) . "$ This result is an extension of an earlier result due to Barlow, Marshall and Proschan (1963). Their result states that mixtures of decreasing hazard-rate distributions also possess decreasing harard rates.

Suppose that there are no true age or tenure effects on separations so that $\hat{s}_{t}\left(t \mid x_{0}, z\right)=0$ everywhere. Then, 
$\hat{s}_{t}\left(t, x_{0}\right)=-\sigma^{2}\left(\hat{s} \mid x_{0}, t\right)$ so that the group separation rate declines although the individual separation rates are constant.Furthermore, $\hat{s}\left(t, x_{0}\right)$ would in this special case be convex in $t$ (which would be consistent with the evidence presented in Table 2 ) if $\sigma^{2}\left(\hat{s} \mid x_{0}, t\right)$ declines monotonically with $t$. For a wide class of distributions $p\left(z \mid x_{0}\right)$ one would expect such a monotonic decline because the selection out of the sample as $t$ increases is such that "movers" are (on average) selected out leaving behind only the "stayers" so that the sample of those left behind becomes increasingly more homogeneous. But $\sigma^{2}$ need not decline monotonically as is demonstrated by the following example. $1 s s u m e$ that at any $x_{0}$, $p\left(z \mid x_{0}\right)$ is such that $z$ takes on only two values, say 1 and 0 , and that the $z=1$ workers have a higher separation propensity than do the $z=0$ workers. $\Lambda$ ssume that the initial $(t=0)$ sample is such that nine-tenths of the workers are $z=1$ types and that the remaining one-tenth are $z=0$ types. Then the initial variance of $z$ is $(1-.9) .9=.09$. As tenure increases, the population proportions shift towards the stayers, and the variance of $z$ increases steadily up to .25 , at which point the population proportions are equal. Thereafter, the variance declines monotonically to zero.of course, a monotonic decline would occur even in this example if the initial proportions happened to be equal, or were weighted in favor of stayers.

Acoording to the first part of equation (18), the change in the group separation rate is always an overstatement (in the negative direction) of the average of the individual changes.However, the same is not true of the group wage-change because the covariance term in the second part of equation (18) may be either positive 
or negative. The relevant question is whether a "mover" (for whom $\hat{s}\left(t, x_{0}\right)-\hat{s}\left(t \mid x_{0}, z\right)$ is negative) would expect to receive higher or lower wages than a "stayer" at a certain tenure- level given that it was optimal for both to remain in the firm up to that time. $\Lambda$ theory which predicts that a worker will separate from a job on which wages paid to him were low relative to his prior expectations implies nothing about this question.

The implications of human capital theory for the sign and magnitude of $\operatorname{Cov}\left(\hat{w}, \hat{s} \mid x_{0}, t\right)$ are ambiguous. In part I we emphasized the role of firm-specific human capital in generating a wedge between the worker's productivity in his current firm and his productivity elsewhere.Consider the polar case in which the ratio of general to firm-specific training is fixed and constant across workers,but that workers differ in the total amount of training that they undertake.Suppose that $z$ is an index inversely related to the worker's propensity to invest in on-the-job training. Under these assumptions, a higher propensity to invest also implies a higher investment in specific training, so that $\hat{s}_{z}\left(t \mid x_{0}, z\right)>0$. Nssume that $z$ is not corelated with unmeasured ability components. Then, since investment in training involves foregone earnings early on in return for higher earnings later, this implies that $w_{z}\left(t \mid x_{0}, z\right)>0$ for young workers (for whom $x_{0}$ and $t$ are small), and $w_{z}\left(t \mid x_{0}, z\right)<0$ for older workers.Therefore $\operatorname{Cov}\left(\hat{w}, \hat{s} \mid x_{0}, t\right)$ is positive for the young and negative for the old workers.

Suppose instead, however, that the total amount of training across individuals (with given $x_{0}$ and $t$ and other observable cha- 
racteristics) is constant while only the ratio of general to specific training varies positively with $z$.Now, high-z workers have higher separation propensities because their training is general in nature rather than firm-specific. In view of the well-known argument (see Becker (1975)) that general training is financed by the workers, such workers earn lower wages initially, and higher wages later on, than do "stayers" whose training is more firm-specific in nature.(Again,this conclusion depends on the assumption that the preference for the type of training is not related to unmeasured ability differences). The implication now is that $\operatorname{Cov}\left(\hat{s},\left.\hat{w}\right|_{x_{0}}, t\right)$ is negative for the young, and positive for the old workers.

Neither polar case is expected to obtain in practice.Both the total amount and the composition of the training may be expected to vary systematically with $z$.But which dominates ? The wage-function estimates reported in Table 6 strongly suggest that the dominant variation is in the total amount of training. In both parts of this table, this inference in made by comparing the second line with the forth line in part $\Lambda$ of Table 6, and the second line with the third in part $B$. The variables PM and NIM are indexer of past mobility and are corelated with $\hat{s}\left(t \mid x_{0}, z\right)$. By definition, $z$ is the unmeasured component of heterogeneity, and the inclusion of $P M$ and $N M M$ therefore has the effect of reducing the absolute value of $\operatorname{Cov}\left(\hat{w}, \hat{s} \mid x_{0}, t\right)$. In both parts of Table 6 there appears to be an effect of this reduction. The wage growth, measured as the sum of the coefficients on $X$ and $T$, increases for the young men when NIM is included, and decreases for the older men when PM is included in the regression, and these changes are consistent with the first polar case,but not the second,as is clear from equation (18). 
Proof of Theoren 3: Substituting for i into (17),

$$
s,\left(t, x_{0}\right)=\frac{f z\left(t \mid x_{0}, z\right) p\left(z \mid x_{0}\right) d z}{\int\left[1-P\left(t \mid x_{0}, z\right) p\left(z \mid x_{0}\right) d z\right.}
$$

Differentlating with respect to $t$ in equation (16).

$$
\hat{p}_{t}\left(z \mid x_{0}, t\right)=\frac{-f\left(t \mid x_{0}, z\right) p\left(z \mid x_{0}\right)}{\int(1-F) p d z}
$$

(20)

$$
\begin{aligned}
& +\frac{\left[l-F\left(t \mid x_{0}, z\right)\right] p\left(z \mid x_{0}\right) f f\left(t \mid x_{0}, z\right) p\left(z \mid x_{0}\right) d z}{[S(1-F) p d z]^{2}} \\
& -\quad\left[-\dot{s}\left(t \mid x_{0}, z\right)+\dot{s}\left(t, x_{0}\right)\right] \hat{p}\left(z \mid x_{0}, t\right)
\end{aligned}
$$

Multiplying both sides by $\hat{s}\left(t \mid x_{0}, z\right)$ and integrating both sides over $z$,

$$
\begin{aligned}
f \dot{s}\left(t \mid x_{0}, z\right) \dot{p}_{t}\left(z \mid x_{0}, t\right) & =\dot{s}\left(t, x_{0}\right)^{2}-f \dot{s}\left(t \mid x_{0}, z\right)^{2} \dot{p} d z \\
& =[E(\dot{s})]^{2}-E\left(\dot{s}^{2}\right)=-\sigma^{2}\left(\hat{s} \mid x_{0}, t\right)
\end{aligned}
$$

and differentiating with respect to $t$ in equation (17) and using equation (21). one obtalns the first assertion of the theorem which has therefore been proved. Next,

$$
\dot{w}\left(x_{0}, t\right)=\int \dot{w}\left(t \mid x_{0}, z\right) \dot{p}\left(z \mid x_{0}, t\right) d z
$$

and differentiating with respect to $t$, 


$$
\begin{aligned}
\dot{w}_{t}\left(x_{0}, t\right)= & f \dot{w}_{t} \hat{p} d z+\rho \hat{w p}_{t} d z \\
= & \int \dot{w}_{t} \hat{p} d z+\rho \hat{w}\left(t \mid x_{0}, z\right)\left[\hat{s}\left(t, x_{0}\right)-\right. \\
& \left.\dot{s}\left(t \mid x_{0}, z\right)\right] \dot{p}\left(z \mid x_{0}, t\right) d z
\end{aligned}
$$

where the second equality follows in view of equation (20),

and this completes the proof of the theorem.

\section{An Estimation Procedure}

The following estimation procedure exploits the property of $p(z \mid x)$ (defined in (15)) of having two different functional forms, implying, in turn, two different functional forms for $\hat{s}\left(t, x_{0}\right)$ in (17). We demonstrate below how identification of the parameters may be secured by subdividing the sample of all workers into two subsamples: one for which $x_{0}=0$ (workers on their first job ever), and the other for which $x_{0}>0$. In fact, in the following illustration for an additive fixed-effect parametrization of $s(t, x, z)$, the parameters are overidentified, which suggests that identification may be secured for more complex functional forms which we hope to consider in future work. The followin additive fixed-effect formulation is perhaps inadequate in capturing the individual differences, but it is adequate as an illustration of the estimation method.Let

(22)

$$
s(t, x, z)=z+s(t, x)
$$

where, without loss of generalfty $S(0,0)=0$. One passible way to proceed is to take first differences in equation (22) and eliminate $z$, thereby also ellminating the selection blas. There are two problems with this approach. Plrst, using differences in separation probabil1tles as the dependent varlable leads to coefficients that are not 
significast. Secondly, there is then no possibility of estimating $\sigma^{2}$, the variance of $\mathrm{z}$. We have therefore chosen a different procedure, which is based on derluing two separate relationships associated with equation (22).

Let $z(t, x)$ be conditional expectation of $z$ and $s(t, x)$ the corsditional expectation of the separation rate given $t$ and $x$. Then, taking conditional expectations in equation (22),

$$
s(t, x)=z(t, x)+s(t, x)
$$

where

$$
z(t, x)=\int z \underline{p}(z \mid x-t, t) d z
$$

Then since

$$
F(t \mid x-t, z)=1-\exp \left\{-2 t-\int_{0}^{t} s(y, x-t+y) d y\right\} .
$$

application of (16) and (15) leads to

$$
\begin{array}{ll}
z(t, x)=\frac{\int z e^{-z t} a(x-t, z) o(z) d z}{\int e^{-z t} a(x-t, z) p(z) d z} & \text { for } x>t, \\
z(x, x)=\frac{\int z e^{-z x} p(z) d z}{\int e^{-z x} p(z) d z} & \text { for } x=t
\end{array}
$$

(workers with $x=t$ are on their first job.) Assume now that $p(z)$ is the normal distribution. Then a strafghtforward calculation yields

$$
z(x, x)=\mu-\sigma^{2} x
$$

where $\mu$ and $\sigma^{2}$ are the mean and variance of $z$. 
So that (for workers on their first job)

$$
g(x, x)=\mu+s(x, x)-\sigma^{2} x
$$

The discontinutty of the $\hat{p}$ distribution at $x=0$ carries over to $z(t, x)$. It is seen from (24) that

$$
z(0,0)=\mu
$$

while taking the linit in (24) and abserving (7),

$$
\lim _{x \rightarrow 0} z(0, x)=\mu+\frac{\sigma^{2}}{\mu}
$$

To abtain a closed-form approximation to $z(t, x)$ for $x>t$, a first-order Taylor's expansion is performed in equation (24) around the point $(t=0, x=\varepsilon)$ where $\varepsilon>0$. Then

$$
\begin{aligned}
z(0, \varepsilon)= & \frac{\int z a(\varepsilon, z) p(z) d z}{\int a(\varepsilon, z) p(z) d z} \\
z_{t}(0, z)= & \frac{\left[\int z^{2} a(\varepsilon, z) p(z) d z+\int z a x(\varepsilon, z) p(z) d z\right]}{\int a(\varepsilon, z) p(z) d z} \\
& +\frac{\left[\int z a(\varepsilon, z) p(z) d z+\int a_{x}(\varepsilon, z) p(z) d z\right] \int z a(\varepsilon, z) p(z) d z}{\left[\int a(\varepsilon, z) p(z) d z\right]^{2}}
\end{aligned}
$$

and

$$
z_{x}(0, \varepsilon)=\frac{\int z a_{x}(\varepsilon, z) p(z) d z}{\int a(\varepsilon, z) p(z) d z}-\frac{\int a_{x}(\varepsilon, z) p(z) d z}{\int a(\varepsilon, z) p(z) d z} \quad z(0, \varepsilon)
$$

For any $x>t$, and any $\varepsilon>0$ no matter how small, 
(26)

$$
\begin{aligned}
z(t, x)=z(0, \varepsilon) & +z_{t}(0, \varepsilon) t+z_{x}(0, \varepsilon)(x-\varepsilon) \\
& + \text { Higher order terms } \\
=\lim _{\varepsilon \rightarrow 0} z(0, \varepsilon)+ & +\varepsilon \rightarrow 0 \\
& +\left[\sum_{t}(0, \varepsilon)\right] t \\
& \left.\varepsilon \rightarrow 0 z_{x}(0, \varepsilon)\right] x \\
& + \text { Higher order terms }
\end{aligned}
$$

Evaluating the limits, and using theorem 1,

$$
\begin{aligned}
& \lim _{c \rightarrow 0} z(0, \varepsilon)=\frac{\int z a(0, z) p(z) d z}{\int a(0, z) p(z) d z}=\frac{\int z s(0,0, z) p(z) d z}{\int s(0,0, z) p(z) d z} \\
& \text { - } \frac{\int z^{2} p(z) d z}{\int z p(z) d z}=\mu+\frac{\sigma^{2}}{\mu} \\
& \lim _{\varepsilon \rightarrow 0} z_{t}(0, \varepsilon)=-\frac{\left[\int z^{2} s(0,0, z) p(z) d z+f z\left[s_{x}(0,0, z)+s_{t}(0,0, z)\right] p(z) d z\right]}{f i s(0,0, z) p(z) d z} \\
& +\frac{\int z s(0,0, z) p(z) d z+\int\left[s_{x}(0,0, z)+s_{t}(0,0, z)\right] p(z) d z}{[f s(0,0, z) p(z) d z]^{2}} \\
& =-\mu^{-1}\left[\int z^{3} p d z+\mu(a+\gamma)\right]+\mu^{-2}\left(\int z^{2} p d z+a+\gamma\right)
\end{aligned}
$$

where $a \equiv s_{x}(0,0)$ and $r=s_{t}(0,0)$

If $g(z)$ is a symetric dstribution so that the third order moment about the mean is equal to zero, then one obtains $\int_{2}{ }^{3}$ pdz $=\mu^{3}+3 \sigma^{2} \mu$, and therefore 


$$
\lim _{\varepsilon \rightarrow 0} z_{t}(0, \varepsilon)=\left(\mu^{-2}-1\right)(\alpha+\gamma)+1-3 \sigma^{2}-\mu^{2}+\frac{\sigma^{2}}{\mu}
$$

Also,

$$
\lim _{\varepsilon \rightarrow 0} z_{x}(0, \varepsilon)=-\frac{\sigma^{2}(\alpha+\gamma)}{\mu^{2}}
$$

Taking an expansion in (23).

$$
s(t, x)=a x+r t+z(t, x)+\text { Hdgher order terns }
$$

But making the substitution into (26),

$$
\begin{aligned}
z(t, x)=\mu+\frac{\sigma^{2}}{\mu}+ & {\left[\left(\mu^{-2}-1\right)(\alpha+\gamma)+1-3 \sigma^{2}-\mu^{2}+\frac{\sigma^{2}}{\mu^{2}}\right] t } \\
& -\frac{\sigma^{2}(\alpha+\gamma) x+\text { Higher order terms. }}{\mu^{2}}+
\end{aligned}
$$

Therefore for $t<x$,

$$
\begin{aligned}
s(t, x)=\mu & +\frac{\sigma^{2}}{\mu}+\left[\left(\mu^{-2}-1\right) \alpha+\mu^{-2} \gamma+1-3 \sigma^{2}-\mu^{2}+\frac{\sigma^{2}}{\mu^{2}}\right] t \\
& +\left[\alpha \quad-\frac{\sigma^{2}}{\mu^{2}}(\alpha+\gamma)\right] x \\
& + \text { Higher order terms. }
\end{aligned}
$$

Also, expanding in (25)

$$
s(x, x)=\mu+\left(\alpha+y-\sigma^{2}\right) x+\text { Higher order terms. }
$$

Equations (27) and (28) are the two basic relationships estimated. 
The separation propensity is of course unobservable. All that is observed is whether or not an individual has changed jobs withis a particular perfod. Let $y=1$ if the worker has changed jobs within the period $(x, x+\Delta x)$, and zero otherwise.

$$
\begin{aligned}
\text { Prob }(y=1) & =1-\exp \left\{-\int_{0}^{\Delta x} s\left(t+y_{1} x+y_{1} z\right) d y\right\} \\
& =s(t, x, z) \Delta x+0\left[(\Delta x)^{2}\right\}
\end{aligned}
$$

similarly

$$
\operatorname{Prob}(y=0)=1-s(t, x, z) \Delta x+0\left[(\Delta x)^{2}\right\}
$$

Therefore $y_{x}$ has a mean equal to $s(t, x, z) \Delta x+0\left\{(\Delta x)^{2}\right\}$

Igmorlog the $O\left[(\Delta x)^{2}\right]$

$$
y_{x}=[z+s(t, x)] \Delta x+u
$$

where $\mu$ is a disturbance with zero mean. In the data $\Delta x$ was equal to two years. The regressions for the separation equations are reported in the first two columns of Table II - 1. (Separate regressions were also run for quits and for layoffs and they are reported in the table, although they do not have an interpretation within the mathematical structure presented above). The three linear coefficients and the two constant terms provide five restrictions on the four parameters so that the parameters are overidentified.However, the relative magnitude of the two constant terms is reverse from that implied by the 
theory, leading to an estimate of $\sigma^{2}$ which is negative, which may mean that the additive fixed-effect formulation is inadequate. In future work, we intend to experiment with different functional forms for the separations and wage equations, focusing on the question concerning the best way to model the individual differences, and to organize the data so that the time interval, $\Delta x$, is shortened to one year rather than two. 


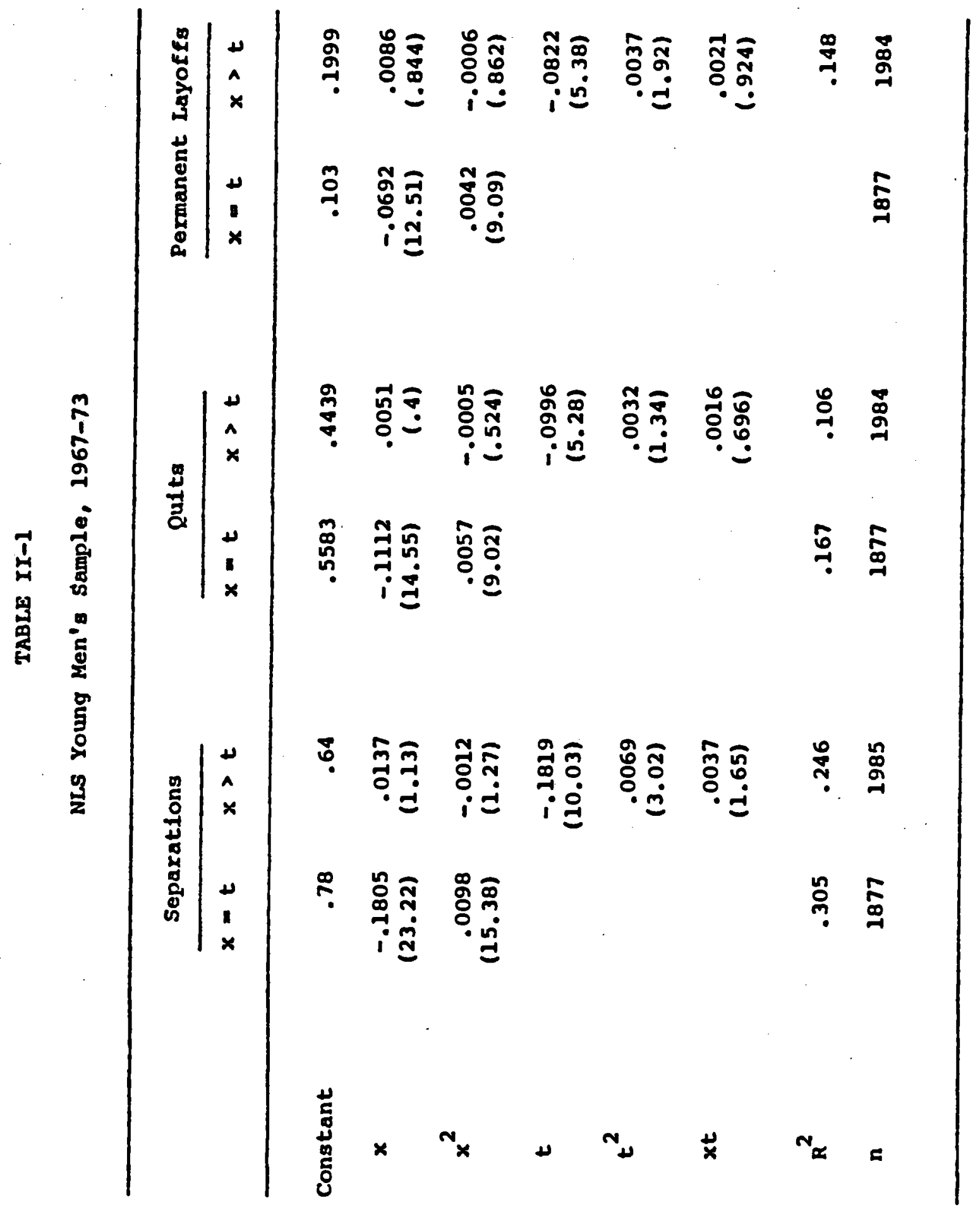




\section{Footnotes}

1 This example was supplied by R. Shakotko.

2 Helpful comments by $J$. Heckman on an earlier version of this paper have led to considerable improvement of this section. 
REFERENCES

Anderson, R., Balcer, Y., and Diamond, D., "A Model of Lifetime Earnings Patterns," Decoupling The Social Security Benefit Structure, Hearings Before the Subcomittee on Social Security, House of Representatives, 94th Congress, 2nd Session, on H.R. 14430, 1976, U.S. Govermment Printing Office.

Barlow, F., Marshall and Proschan, "Properties of Distributions with Monotone Hazard Rates," Annals of Mathematical Statistics, 1963.

Bartel, A., "Job Mobility and Earnings Growth," NBER Working Paper No. 117, 1975. 1977.

- "The Economics of Migration," NBER Working Paper No. 198,

Becker, G.S., Human Capital, 2nd ed., Columbia Univers1ty Press, 1975.

Blumen, I.M., Kogan, M., and MCCarthy, P.J., The Industrial Mobility of Labor as a Probability Process, Cornell University Press, 1955.

BIS, Job Mobility in 1961, Special Labor Force Report No. 35, 1963.

BIS, Job Tenure of Workers 1973, Special Labor Force Report No. 172, 1975.

Borjas, G., "Job Mobility and Earnings Growth Over the Life Cycle," Ph.D. Thesis, Columbia University, 1975.

' "Labor Turnover in the Union and the Public Sector, Xerox, 1978.

Borjas, G., and Mincer, J., "The Distribution of Earnings Profiles in Iongitudinal Data", in Income Distribution and Economic Inequality, Edited by Zvi Griliches, John Wiley \& Sons, N.Y., 1978.

Brown, A.W., "A Note on the Use of a Pearson Type III Function in Renewal Theory," Annals of Mathematical Statistics, 1940. pp. 448-453.

Burdett, X., "On-the-Job Search," Northwestern University, Ph.D. Thesis, 1973.

Feller, W., Introduction to Probability, II, Wiley, 1966.

Freeman, R., "Exit-Voice Tradeoff in the Labor Market," unpublished, Harvard University, April 1978. 
Heckman, J., "Statistical Models for Discrete Panel Data," Xerox, 1977.

Heckman, J., and Willis, R., "A Beta Logistic Model for the Analysis of Sequential Labor Force Participation of Women," Journal of Political Econouy, February 1977.

Jovanovic, B., "Iabor Turnover where Jobs are Pure Search Goods," unpublished, Columbia University, February $1978(a)$.

- "Job-Matching and the Theory of Turnover," University of Chicago, Ph.D. Thesis, 1978.

Leighton, L., "Unemployment over the Life-Cycle," Ph.D. Thesis, Columbia University, 1978.

Mincer, J., Schooling, Experience and Earnings, NBER, 1974.

- "Fanily Migration Decisions," Journal of Political Economy. October 1978.

Mortensen, D., "Specific Capital and Labor Turnover", Bell Journal, Fall 1978.

Nelson, P., "Information and Consumer Behavior," Journal of political Economy, 1970.

Parnes, H.S., "Labor Force Participation and Labor Mobility," in A Review of Industrial Relations Research, Vol. 1, 1970.

Parsons, D., "Models of Labor Turnover," Ohio State University, 1975.

, "Speciflc Human Capital: Quits and Layoffs," Journal of Political Economy, November 1972.

Rosen, S., "Short-Rus Employment Variation on Railroads, Ph.D. Thesis, University of Chicago, 1966.

Singer, B., and Spilerman, S., "Some Methodological Issues in the Analysis of Longitudinal Surveys," Annals of Economic and Social Measurement, NBER, Fall, $197 \overline{6}$

Sorensen, A., "Growth in Occupational Achievement," in Social Incicator Models, Russell Sage Foundation, 1975.

Stigler, G.J., "Economics of Information," Journal of Political Economy, June 1961.

Tuma, N.B., "Rewards, Resources, and the Rate of Mobility," American Sociological Review, April 1976. 